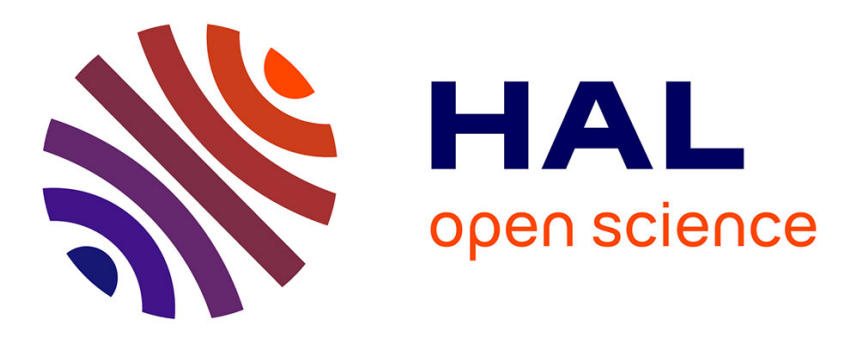

\title{
Understanding the Mechanism of Lithium Ion Extraction using Tributyl Phosphate in Room Temperature Ionic Liquid
}

Abderrazak Masmoudi, Guillaume Zante, Dominique Trebouet, Rémi Barillon, Maria Yu Boltoeva

\section{To cite this version:}

Abderrazak Masmoudi, Guillaume Zante, Dominique Trebouet, Rémi Barillon, Maria Yu Boltoeva. Understanding the Mechanism of Lithium Ion Extraction using Tributyl Phosphate in Room Temperature Ionic Liquid. Solvent Extraction and Ion Exchange, 2020, 10.1080/07366299.2020.1788201. hal-02901266

\section{HAL Id: hal-02901266 \\ https://hal.science/hal-02901266}

Submitted on 17 Jul 2020

HAL is a multi-disciplinary open access archive for the deposit and dissemination of scientific research documents, whether they are published or not. The documents may come from teaching and research institutions in France or abroad, or from public or private research centers.
L'archive ouverte pluridisciplinaire HAL, est destinée au dépôt et à la diffusion de documents scientifiques de niveau recherche, publiés ou non, émanant des établissements d'enseignement et de recherche français ou étrangers, des laboratoires publics ou privés. 
Understanding the Mechanism of Lithium Ion Extraction using Tributyl

Phosphate in Room Temperature Ionic Liquid

Abderrazak Masmoudia*, Guillaume Zante ${ }^{\mathrm{a}, \mathrm{b}}$, Dominique Trébouet ${ }^{\mathrm{a}}$, Rémi Barillon $^{\mathrm{a}}$, Maria Boltoeva ${ }^{\mathrm{a}}$

${ }^{a}$ Université de Strasbourg, CNRS, Institut Pluridisciplinaire Hubert Curien (IPHC), UMR7178, F-67000 Strasbourg, France

${ }^{b}$ ADEME, 20 Avenue du Grésillé, 49004 Angers Cedex 01, France

*Corresponding author: abderrazak.masmoudi@iphc.cnrs.fr 


\section{Understanding the Mechanism of Lithium Ion Extraction using Tributyl Phosphate in Room Temperature Ionic Liquid}

\section{Abstract}

This paper reports the liquid-liquid extraction behavior of lithium ions from aqueous solutions containing hydrochloric acid using a well-known neutral extractant tri- $n$-butyl phosphate (TBP) and commonly used imidazolium-based ionic liquids (IL). The effect of several experimental parameters on the lithium partitioning was examined, in particular the nature of counter anions, the concentration of TBP, the $\mathrm{pH}$ of the aqueous solutions and the initial lithium ion concentration. The lithium extraction was also investigated with a conventional organic solvent 1-octanol to understand the role of the IL in the extraction process. Our results suggest that lithium partition into TBP/IL system proceeds via two mechanisms, namely by cationic exchange and ion pair transfer. The corresponding extraction equilibrium constants as well as stoichiometry of extracted complexes were determined. To overcome the loss of ionic liquid by cation exchange, we have shown that TBP mixed with an ionic liquid possessing low solubility in aqueous phases can extract lithium when a highly hydrophobic counter-ion such as $\left(\mathrm{Tf}_{2} \mathrm{~N}^{-}\right)$is present in the aqueous phase.

Keywords: Lithium, solvent extraction, tri-n-butyl phosphate, imidazolium-based ionic liquids 


\section{Introduction}

Lithium ( $\mathrm{Li}$ ) is considered at least at the short and medium term as a key element for modern battery and energy storage technology. Its unique physical and chemical properties have made of it the main component of rechargeable batteries. At present, lithium-ion batteries (LIBs) represent $37 \%$ of the rechargeable battery world market [1].

In recent years, the battery production has been increased significantly because of the electrification of transport and the growth of electronic device use. Today, lithium consumption for batteries is about $39 \%$ of its worldwide production It is clear that by further increasing battery production, which has already increased considerably in recent years, lithium demand will continue to increase in the coming years $[2,3]$. To ensure supply security and balance of lithium consumption-production without increasing considerably its price, we must resort to recover lithium from both primary and secondary resources such as spent LIBs.

There are a lot of techniques to recover metals from aqueous solutions, such as precipitation, electrolysis, evaporation, or crystallization, etc., but hydrometallurgical processes are often used for the extraction and separation of metals. Among the hydrometallurgical processes, solvent extraction is a proven technique, mainly due to its low operational costs, the possibility to deal with low metal concentrations and its good selectivity.

In recent years, more interest has been brought to the use of hydrophobic ionic liquids (ILs) in solvent extraction. ILs consist only of ionic species and possess low melting temperature, namely below the boiling point of water $\left(100^{\circ} \mathrm{C}\right)$. ILs that are liquid at room temperature, are called Room-Temperature Ionic Liquids (RTILs). The ILs importance has only recently been recognized. It goes in parallel with the awareness of the dangers threatening the environment as air and water pollution. ILs have been considered as potential alternatives to volatile organic compounds (VOCs) having a negative impact on the 
environment and human health [4]. Aiming to extract lithium by liquid-liquid extraction, our interest for ILs is in the same perspective, namely, to replace the conventional molecular solvents, or at least to reduce their use, but also to improve extraction efficiency and selectivity, and to understand underlying extraction mechanisms.

Since 1998, when a first published study showed the possibility to extract substituted benzene from an aqueous phase into 1-butyl-3-methylimidazolium hexafluorophosphate ionic liquid ([ $\left.\left.\mathrm{C}_{4} \mathrm{mim}\right]\left[\mathrm{PF}_{6}\right]\right)$, several research groups around the world have carefully studied the use of ionic liquids in solvent extraction. It is now well established that metal extraction with ILs is more complicated than that with conventional solvents. Therefore, a lot of researchers insist that future research focus should be on the understanding of extraction mechanisms, which is very important for the better design of extraction systems and their commercialization [5]. Our work is in the same perspective.

Concerning solvent extraction of lithium, a number of studies using various ILs have been reported. Researchers explored to employ ILs mainly in four different manners. Whether using neat IL as extracting phase, X. Zhao et al [6] tested a series of ILs composed of anionic entities that had intensive affinity to the lithium ion and highly hydrophobic cations. The IL providing the highest extraction efficiency for lithium cations is tetrabutylammonium mono2-ethylhexyl(2-ethylhexyl)phosphate (abbreviated as $\left[\mathrm{N}_{4444}\right][$ EHPMEH]). C. Shi et al examined the extraction of lithium cations using novel phosphonium IL as an extracting agent diluted in molecular solvents, and also using non-fluorinated tetraalkylammonium-based functionalized ionic liquids $[7,8]$. In these studies, it was found that an ionic liquid tetrabutylphosphonium bis(2,4,4-trimethylpentyl) phosphinate ([ $\left.\left.\mathrm{P}_{4444}\right][\mathrm{BTMPP}]\right)$, diluted in toluene and ionic liquids (ILs), namely tetrabutylammonium bis(2-ethylhexyl)-phosphate $\left(\left[\mathrm{N}_{4444}\right][\mathrm{DEHP}]\right)$, and tetraoctylammonium bis(2-ethylhexyl)-phosphate $\left(\left[\mathrm{N}_{8888}\right][\mathrm{DEHP}]\right)$, can be used to extract selectively lithium ions from aqueous solutions. 
The lithium extraction was also studied intensively with ILs as diluents for classical extractants. The extraction system with several imidazolium-based ionic liquids associated with tri- $n$-butyl phosphate (TBP) extractant has been investigated numerous times [9-15]. It was found that this system can highly extract lithium from aqueous solutions. Moreover, it is suitable for the separation of magnesium $(\mathrm{Mg})$ and lithium in the high $\mathrm{Mg} / \mathrm{Li}$ ratio brines. $\mathrm{A}$ cation exchange has always been touted as the only mechanism for lithium extraction, without always giving the same stoichiometry of the complex formed.

D. Gao et al $[16,17]$ have investigated a similar system containing imidazolium based ionic liquids, tri-isobutyl phosphate (TIBP) and kerosene. In the first study, a neutral extraction mechanism was proposed, while a cation exchange was proposed in the second one, where the effect of increasing the alkyl chain of the IL cation was investigated. Imidazolium ionic liquids were favored, since they are well studied and have low viscosities, thus facilitating their handling in liquid-liquid extraction [18].

In the present work, the extraction of lithium by a similar system based on 1-ethyl-3methylimidazolium bis(trifluoromethylsulfonyl)imide ionic liquid $\left[\mathrm{C}_{2} \mathrm{mim}\right]\left[\mathrm{Tf}_{2} \mathrm{~N}\right]$ and tri-nbutyl phosphate (TBP) is evaluated. Our main aim is to give a complete mechanistic description of the extraction of lithium cations by $\mathrm{TBP}$ diluted in $\left[\mathrm{C}_{2} \mathrm{mim}\right]\left[\mathrm{Tf}_{2} \mathrm{~N}\right]$, particularly to determine the stoichiometric coefficients of the extracted species and corresponding equilibrium constants. The results of this study can be also interesting for the extraction of other metals by neutral extractants in ILs, in order to fill the lack of the understanding of the extraction mechanisms.

\section{Materials and Methods}

The ionic liquids (purity 99.5\%) were purchased from Solvionic (France) and used without any further purification. The chemical structure of the ionic liquids used in the present work is 
shown in Figure 1.

Tri-n-butyl phosphate (TBP, purity $>99 \%$ ) liquid at room temperature was purchased from Acros Organics (Belgium). Concentrated hydrochloric and nitric acids were obtained from VWR (France) having purities of $35 \mathrm{wt} \%$ and $67 \mathrm{wt} \%$, respectively. Lithium bis(trifluoromethanesulfonyl)imide salt $\left(\operatorname{LiTf}_{2} \mathrm{~N}\right)($ purity $>99 \%)$ and hydrogen bis(trifluoromethanesulfonyl)imide $\left(\mathrm{HTf}_{2} \mathrm{~N}\right)$ (purity $\left.>95 \%\right)$ were purchased from Solvionic (France) and Sigma Aldrich, respectively.

Lithium chloride ( $\mathrm{LiCl}$ ) salt with purity above $99 \%$ was purchased from PROLABO. Deuterium oxide $\left(\mathrm{D}_{2} \mathrm{O}\right)$ and deuterated nitric acid solutions $\left(\mathrm{DNO}_{3}\right)$ were obtained from Sigma Aldrich with a purity of deuterium atom of $99 \%$. Sodium trifluoroacetate $\left(\mathrm{CF}_{3} \mathrm{COONa}\right.$, 98\%) was purchased from Alfa Aesar. Dihydrated sodium citrate $\left(\mathrm{C}_{2} \mathrm{H}_{2} \mathrm{NaO}_{6} .2 \mathrm{H}_{2} \mathrm{O}, 99 \%\right)$ was purchased from Merck. Aqueous acidic solutions were prepared using deionized water (resistivity of $18.2 \mathrm{M} \Omega . \mathrm{cm}$ ).

\section{Solvent Extraction experiments}

In this paper, the following notation is used to facilitate reading: Aqueous phase $=$ (Metal salt/Aqueous solution) // (Extracting agent/Diluent) $=$ Organic phase. The aqueous phases were prepared by dissolution of some amount of metal salt in water, and then, the acidity was adjusted by adding appropriate aliquots of $\mathrm{HCl}, \mathrm{HNO}_{3}, \mathrm{DNO}_{3}$ or $\mathrm{HTf}_{2} \mathrm{~N}$. The acidity was measured by a pH meter (EUTECH INSTRUMENTS, pH2100x) or by acid-base titration (Titroline) with $\mathrm{NaOH}$, when $\mathrm{pH}$ was lower than 1 . The organic phase was prepared by mixing the appropriate amounts of TBP and $\left[\mathrm{C}_{n} \operatorname{mim}\right]\left[\mathrm{Tf}_{2} \mathrm{~N}\right](n=2$ or 8$)$ or 1-octanol to obtain the desired volume ratio. The extraction experiments were conducted by mixing defined volumes (typically, $0.8 \mathrm{~mL}$ ) of aqueous and organic phases in an Eppendorf tube (2 
$\mathrm{mL})$. The volume ratio between two phases was 1:1 in all experiments.

All distribution experiments were carried at room temperature $25 \pm 2{ }^{\circ} \mathrm{C}$. The liquidliquid mixture was shaken mechanically using a Thermo-shaker (BIOSAN-TS100) for a defined time (preliminary results have shown that a mixing time of $10 \mathrm{~min}$ is sufficient to reach the equilibrium) at $1400 \mathrm{rpm}$. After agitation and centrifugation at $5000 \mathrm{rpm}$ for $2 \mathrm{~min}$ with a VWR Micro Star 12 centrifuge, the two immiscible phases were separated carefully to avoid cross contamination of the phases.

\section{Aqueous Concentrations of Solutes}

An aliquot of the aqueous phase was diluted by 1 vol. \% hydrochloric acid solution to analyze metal ions concentrations by Inductively Coupled Plasma Optic Emission Spectroscopy (ICPOES) using a Varian 720-ES apparatus. Five standards solutions were prepared in the same matrices as samples and used for calibration. These analyses allowed us to determine the metal ions concentration in the initial and equilibrium aqueous phases. The distribution coefficient is then determined according to the following equation:

$$
\mathrm{D}=\frac{[\mathrm{M}]_{\mathrm{org}}}{[\mathrm{M}]_{\mathrm{aq}}}=\frac{[\mathrm{M}]_{\text {init }}-[\mathrm{M}]_{\mathrm{aq}}}{[\mathrm{M}]_{\mathrm{aq}}} \frac{\mathrm{V}_{\mathrm{aq}}}{\mathrm{V}_{\mathrm{org}}}
$$

The subscripts, "aq" and "org" represent the aqueous and the organic phase, respectively. Knowing that the volume ratio used in this work was equal to 1 , and that at equilibrium, no variation in phase volumes was observed, the Eq. (1) becomes:

$$
\mathrm{D}=\frac{[\mathrm{M}]_{\mathrm{org}}}{[\mathrm{M}]_{\mathrm{aq}}}=\frac{[\mathrm{M}]_{\text {init }}-[\mathrm{M}]_{\mathrm{aq}}}{[\mathrm{M}]_{\mathrm{aq}}}
$$

Where $[\mathrm{M}]_{\text {init }}$ and $[\mathrm{M}]_{\mathrm{aq}}$ are metal concentrations before and after extraction in the aqueous phase, respectively. 
The concentration of the ionic liquid anions $\left(\mathrm{Tf}_{2} \mathrm{~N}^{-}\right)$in the aqueous phases was determined by quantitative fluorine-19 nuclear magnetic resonance spectroscopy ( ${ }^{19} \mathrm{~F}$ qNMR). This method is based on the fact that the signal intensity (I) in the NMR spectrum is directly proportional to the number of nuclei $(\mathrm{N})$ contained in the sample and responsible for that resonance [19]:

$$
\mathrm{I}_{\mathrm{x}}=\mathrm{K}_{\mathrm{s}} \cdot \mathrm{N}_{\mathrm{x}}
$$

Where $\mathrm{K}_{\mathrm{s}}$ is the spectrometer constant. This technique requires a reference compound (also called an internal standard) with a signal well separated from the signal of the sample to avoid interferences. Sodium trifluoroacetate $\left(\mathrm{CF}_{3} \mathrm{COONa}\right)$ was used as an internal standard, which shows one peak at $-76.6 \mathrm{ppm}$ in $\mathrm{D}_{2} \mathrm{O}$, corresponding to its 3 equivalents fluorine atoms. A weighted amount of $\mathrm{CF}_{3} \mathrm{COONa}$ salt was dissolved in a known volume of $\mathrm{D}_{2} \mathrm{O}$, then an aliquot of this solution was added to our sample where the concentration of $\mathrm{Tf}_{2} \mathrm{~N}^{-}$was unknown. The concentration of $\mathrm{Tf}_{2} \mathrm{~N}^{-}$was calculated then by integration of the peaks, using the following equations:

$$
\begin{aligned}
& \frac{\mathrm{n}_{\mathrm{x}}}{\mathrm{n}_{\mathrm{std}}}=\frac{\mathrm{I}_{\mathrm{x}}}{\mathrm{I}_{\mathrm{std}}} \frac{\mathrm{N}_{\text {std }}}{\mathrm{N}_{\mathrm{x}}} \\
& \mathrm{C}_{\mathrm{x}}=\frac{\mathrm{I}_{\mathrm{x}}}{\mathrm{I}_{\text {std }}} \frac{\mathrm{N}_{\text {std }}}{\mathrm{N}_{\mathrm{x}}} \frac{\mathrm{V}_{\text {std }}}{\mathrm{V}_{\mathrm{x}}} \mathrm{C}_{\text {std }}
\end{aligned}
$$

Where $C_{x}$ and $C_{\text {std }}$ are the analyte concentration and the internal standard concentration, respectively. $\frac{n_{x}}{n_{s t d}}$ is the molar ratio of the analyte and the standard. $\frac{N_{\text {std }}}{N_{x}}$ and $\frac{I_{x}}{I_{\text {std }}}$ correspond to the number of spins ratio and the integrated signal area ratio of a typical NMR peak of the analyte and the standard. $\frac{\mathrm{V}_{\text {std }}}{\mathrm{V}_{\mathrm{x}}}$ is the volume ratio of the standard and sample aliquots.

The concentration of $\mathrm{C}_{2} \mathrm{mim}^{+}$cations in the hydrochloric acid solutions was determined by UV-Vis absorption spectroscopy $\left(\lambda_{\max }=211 \mathrm{~nm}, \varepsilon=4397.7 \mathrm{~cm}^{-1} \cdot \mathrm{mol}^{-1} \cdot \mathrm{dm}^{3}\right.$ 
[20]). This is not possible when using a nitric acid solution as aqueous phase because of the overlapping of the adsorption band with $\mathrm{NO}_{3}{ }^{-}$.For this reason, quantitative ${ }^{1} \mathrm{H}$ NMR was used, and $\mathrm{DNO}_{3}$ used instead of $\mathrm{HNO}_{3}$. Sodium citrate tetrahydrate $\left(\mathrm{C}_{2} \mathrm{H}_{5} \mathrm{NaO}_{6} \cdot 4 \mathrm{H}_{2} \mathrm{O}\right)$ was the suitable internal standard for these measurements. It has a quadruplet between 2.4 and 2.8 ppm in $\mathrm{D}_{2} \mathrm{O}$. The experimental protocol using quantitative NMR for the determination of ILs constituents used in this study was developed by Mazan and co-workers [21]. Analyses were carried at room temperature using a $300 \mathrm{MHz}$ NMR instrument.

All experiments were conducted in duplicate and results indicated standard deviations lower than $10 \%$.

\section{Results and Discussions}

\section{Effect of Organic and Aqueous Phase Compositions}

To assess the extraction behavior of $\mathrm{Li}$ with TBP, its distribution between an aqueous acidic solution and organic phase was studied as a function of the extracting agent concentration in the organic phase. Two different organic phases were studied, namely one composed of $\mathrm{TBP} /\left[\mathrm{C}_{2} \mathrm{mim}\right]\left[\mathrm{Tf}_{2} \mathrm{~N}\right]$ and another one composed of $\mathrm{TBP} / 1$-octanol, as a matter of comparison

(Figure 2). On the other hand, two different aqueous phases $\left(\mathrm{HCl}\right.$ or $\mathrm{HNO}_{3}$ solutions) were used to study the effect of the counter-ion present in the aqueous phase. The extractant dependency data for lithium extraction is shown in Figure 2. The lithium extraction with neat TBP $(100 \%)$, neat IL $\left(\left[\mathrm{C}_{2} \mathrm{mim}\right]\left[\mathrm{Tf}_{2} \mathrm{~N}\right]\right)$ or TBP diluted in 1-octanol is negligible whatever the counter-ion present in the aqueous phase. Therefore, the extraction of neutral species composed of $\mathrm{LiCl}$ and TBP molecules could be excluded.

A significant lithium extraction was observed only when $\left[\mathrm{C}_{2} \operatorname{mim}\right]\left[\mathrm{Tf}_{2} \mathrm{~N}\right] \mathrm{IL}$ was introduced in the system with TBP. High distribution ratios of lithium were obtained when TBP concentration was above 40 vol. \% whatever the kind of the aqueous media, 
hydrochloric or nitric. This means that the extraction of lithium ions is not governed by the type of counter-ion present in the aqueous phase. The extraction efficiency reached a maximum when the TBP concentration is between 80 vol.\% and 90 vol.\%. Further increase of TBP concentration in the organic phase leads to an exponential drop of the lithium extraction efficiency, and the appearance of a third phase when TBP concentration is higher than 95 vol.\%. These observations show that both compounds, TBP and $\left[\mathrm{C}_{2} \operatorname{mim}\right]\left[\mathrm{Tf}_{2} \mathrm{~N}\right]$ are necessary to the efficient extraction of Li. Gao et al. [16] proposed as mechanism of extraction solvation of LiCl by TIBP. Shi et al [11] [14] [9], proposed a cation exchange mechanism, in which the lithium ion is complexed by TBP and transferred into the organic phase, while the IL cation is exchanged and back-transferred into the aqueous phase.

In order to follow the variation of each constituent IL ion $\left(\left[\mathrm{Tf}_{2} \mathrm{~N}^{-}\right]_{\mathrm{aq}}\right.$ and $\left.\left[\mathrm{C}_{2} \mathrm{mim}^{+}\right]_{\mathrm{aq}}\right)$ in the aqueous phase as a function of lithium extraction, their concentrations in the case of $\mathrm{LiCl} / \mathrm{HCl} / / \mathrm{TBP} /\left[\mathrm{C}_{2} \mathrm{mim}\right]\left[\mathrm{Tf}_{2} \mathrm{~N}\right]$ (Figure 2) were measured and the results are presented in Figure 3. To make the difference between variations related to lithium extraction and variations related to $\mathrm{TBP} /\left[\mathrm{C}_{2} \mathrm{mim}\right]\left[\mathrm{Tf}_{2} \mathrm{~N}\right]$ volume ratio, the same experiment was repeated with and without lithium in the aqueous phase. Results revealed that by increasing TBP concentration, the $\mathrm{C}_{2} \mathrm{mim}^{+}$aqueous solubility remains approximately stable and decrease above around 50 vol. \% of TBP. On the other hand, an increase in TBP concentration is accompanied by a gradually decrease of $\mathrm{Tf}_{2} \mathrm{~N}^{-}$aqueous solubility. It shows also that $\left[\mathrm{C}_{2} \mathrm{mim}^{+}\right]_{\mathrm{aq}}$ is higher in the presence of lithium rather than without lithium, but the opposite trend is observed for $\left[\mathrm{Tf}_{2} \mathrm{~N}^{-}\right]_{\mathrm{aq}}$. The IL parts aqueous concentrations at high TBP concentrations are not equal even without lithium and the electro-neutrality is not respected. This means that some phenomenon happens at high TBP concentrations, which we are not yet capable to describe here. The influence of increasing TBP concentration on IL cation solubility has already been studied by Rickert and coworkers [22] and Gaillard and coworkers 
[23]. Rickert found that when using $\mathrm{HNO}_{3}(1 \mathrm{M})$ as aqueous phase, increasing neutral organophosphorus reagent concentration in $\left[\mathrm{C}_{5} \mathrm{mim}\right]\left[\mathrm{Tf}_{2} \mathrm{~N}\right]$ leads to an increase of the $\mathrm{C}_{5} \mathrm{mim}^{+}$aqueous-phase concentrations. Gaillard found also that the $\mathrm{C}_{4} \mathrm{mim}^{+}$aqueous-phase concentrations in $3.7 \mathrm{M} \mathrm{HNO}_{3}$ solution at equilibrium increases as a function of the TBP concentration in $\left[\mathrm{C}_{4} \mathrm{mim}\right]\left[\mathrm{Tf}_{2} \mathrm{~N}\right]$.

\section{Effect of Aqueous Phase pH}

The effect of the initial $\mathrm{pH}$ of the aqueous solution on the extraction of lithium by $\mathrm{TBP} /\left[\mathrm{C}_{2} \mathrm{mim}\right]\left[\mathrm{Tf}_{2} \mathrm{~N}\right]$, was investigated. Three types of acidic media were tested, namely hydrochloric, nitric and bistriflimic $\left(\mathrm{HTf}_{2} \mathrm{~N}\right)$ acid. As illustrated in Figure 4, the distribution ratio of lithium depends on the aqueous $\mathrm{pH}$. It is interesting to notice that a small variation of the lithium distribution ratio is observed using neither chloride nor nitrate as counter-ion. It seems that the counter-ion has a slight influence on the extraction of lithium. When using the rather lipophilic nitrate anion as counter-ion, the distribution ratio of lithium is a little bit higher than with $\mathrm{Cl}^{-}$anion. That means that $\mathrm{NO}_{3}{ }^{-}$, in contrast to $\mathrm{Cl}^{-}$, contribute by a small proportion to the extraction of lithium. Using $\operatorname{HTf}_{2} \mathrm{~N}$, It seems that it is difficult to compare the effect of $\mathrm{Tf}_{2} \mathrm{~N}^{-}$with that of $\mathrm{NO}_{3}{ }^{-}$or $\mathrm{Cl}^{-}$, because $\mathrm{Tf}_{2} \mathrm{~N}^{-}$is an IL constituent. In fact, as we will see bellow, the IL solubility decreases due to the presence of $\mathrm{Tf}_{2} \mathrm{~N}^{-}$in the aqueous phase, according to Le Châtelier's principle. The cation exchange mechanism is less probable in this system, but we observe an extraction of lithium, probably due to the extraction of the neutral species $\left(\mathrm{LiTf}_{2} \mathrm{~N}\right)$ by TBP.

In highly acidic media $(\mathrm{pH}<1)$ the lithium extraction is low in all acidic solutions. This has been observed in several similar systems using imidazolium ionic liquids associated to tributyl phosphate $[14,17]$. In the case of hydrochloric and nitric acid solutions, it could be attributed to a strong competition between the extraction of lithium and the extraction of protons by TBP. Indeed, at high acidic medium, there is a considerable quantity of protons 
moved to the organic phase as can be seen in Figure 5. In the case of $\operatorname{HTf}_{2} \mathrm{~N}$ acid solution, $\mathrm{HTf}_{2} \mathrm{~N}$ is transferred into the organic solution, thus reducing the amount of $\mathrm{Tf}_{2} \mathrm{~N}^{-}$anions available in the aqueous phase to form ion pairs with lithium. At medium and low acidic solutions, the distribution coefficient of lithium increased significantly, because there are fewer protons in the feed solution and therefore less protons extracted to the organic phase.

For each $\mathrm{pH}$ value, the concentrations of the IL constituent ions in the equilibrium aqueous solutions were measured and presented in Figure 6. It was observed that the $C_{2} \mathrm{mim}^{+}$ solubility in $\mathrm{HCl}$ and $\mathrm{HNO}_{3}$ is high in highly acidic solutions, probably due to an exchange with protons extracted to the organic phase. It could also be due to the high concentration of the conjugated bases $\left(\mathrm{NO}_{3}{ }^{-}, \mathrm{Cl}^{-}\right)$. The higher their concentration, the easier for the IL anion $\left(\mathrm{Tf}_{2} \mathrm{~N}^{-}\right)$to be exchanged. It generates $\left[\mathrm{C}_{2} \mathrm{mim}\right][\mathrm{X}]$, which is more hydrophilic and leads to an increase of the imidazolium cation concentration in the aqueous phase. Then, $\mathrm{C}_{2} \mathrm{mim}^{+}$ solubility decreases considerably by increasing the $\mathrm{pH}$, until it reaches a plateau at a $\mathrm{pH}$ near to 3. In the case of $\operatorname{HTf}_{2} \mathrm{~N}$, the IL solubility is low in highly acidic solution due to the presence of high concentration of $\mathrm{Tf}_{2} \mathrm{~N}^{-}$in the aqueous phase, according to Le Châtelier's principle. On the other hand, the opposite trend is observed for $\mathrm{Tf}_{2} \mathrm{~N}^{-}$. Its aqueous concentration is low in highly acidic solutions and increases with the $\mathrm{pH}$. This effect was already observed [24] and explained by the fact that $\mathrm{Tf}_{2} \mathrm{~N}^{-}$associates with $\mathrm{H}^{+}$and return to the organic phase (the conditional extraction constant of $\mathrm{HTF}_{2} \mathrm{~N}$ is $\mathrm{K}_{\mathrm{HTF}_{2} \mathrm{~N}}=14100$ [25]). The change of ILs ions solubility as a function of the aqueous phase acidity was already studied [23]. This trend was observed even in the absence of TBP in organic phase, and it seems that the introduction of TBP enhanced these phenomena. 


\section{Loading of Lithium}

The extraction of lithium was examined with various initial concentrations of lithium in the

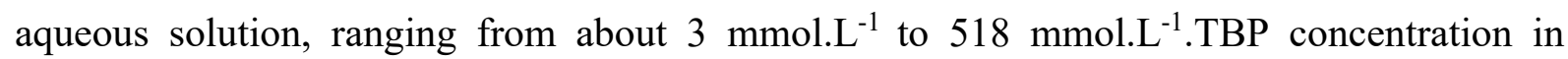
$\left[\mathrm{C}_{2} \mathrm{mim}\right]\left[\mathrm{Tf}_{2} \mathrm{~N}\right]$ used in this experiment was 40 vol. $\%$, and a neutral solution was used as aqueous phase, in order to avoid competition between lithium cations and protons. As it is shown in Figure 7a, even if the absolute amount of lithium ion transferred into the organic phase increased the lithium distribution ratio decreased significantly with an increase in lithium initial concentration. In parallel, the aqueous concentrations of the IL constituents were measured. Results are displayed as a function of the initial lithium concentration on Figure $7 \mathrm{~b}$. This figure shows that by increasing the initial lithium concentration, the equilibrium aqueous concentration of $\mathrm{C}_{2} \mathrm{mim}^{+}$increased, and that of $\mathrm{Tf}_{2} \mathrm{~N}^{-}$decreased. This is most likely due to the occurrence of two reactions upon extraction of lithium by TBP dissolved in the ionic liquid. The first one is cation exchange, where $\mathrm{C}_{2} \mathrm{mim}^{+}$substitutes charged $\mathrm{Li}^{+}$species in the aqueous phase, to ensure electrical neutrality. The second one is ion pair transfer process, where $\mathrm{Tf}_{2} \mathrm{~N}^{-}$initially solubilized in the aqueous phase acts as counter-ion and is extracted with $\mathrm{Li}^{+}$from the aqueous phase.

It is quite known that salts influence the solubility of ILs $[26,27]$. To ensure that the observed IL constituents solubility variation is indeed due to the extraction of lithium and not to the lithium chloride "salting-out" effect, a pure IL phase (without TBP) was agitated with different lithium salt concentrations in the aqueous phase. Then, the IL cation concentration was measured, and it was found that the ionic liquid solubility was not affected significantly by the $\mathrm{Li}$ ion concentration in aqueous phase. That is to say, the IL solubility variation seen in the Figure $7 \mathrm{~b}$ is due to the extraction of lithium by TBP. 
Therefore, in the system of $\mathrm{LiCl} / \mathrm{HCl} / / \mathrm{TBP} /\left[\mathrm{C}_{2} \operatorname{mim}\right]\left[\mathrm{Tf}_{2} \mathrm{~N}\right]$ lithium ion extraction could be described by an ion-exchange, according to the equation (6), and by ion pair transfer process according to equation (7):

$$
\begin{gathered}
\mathrm{Li}_{\mathrm{aq}}^{+}+n \mathrm{TBP}_{\text {org }}+\mathrm{C}_{2} \mathrm{mim}_{\text {org }}^{+} \rightleftarrows[\mathrm{Li} \cdot n \mathrm{TBP}]_{\text {org }}^{+}+\mathrm{C}_{2} \mathrm{mim}^{+}{ }_{\text {aq }} \\
\mathrm{Li}_{\text {aq }}^{+}+m \mathrm{TBP}_{\text {org }}+\mathrm{Tf}_{2} \mathrm{~N}_{\mathrm{aq}}^{-} \rightleftarrows\left[\mathrm{Li} \cdot m \mathrm{TBP} . \mathrm{Tf}_{2} \mathrm{~N}\right]_{\text {org }}
\end{gathered}
$$

Where, $n$ and $m$ represent the number of TBP molecules involved to complex with lithium ion according to an ion-exchange mechanism or a neutral extraction mechanism, respectively.

Furthermore, if and only if these two reactions are involved in the extraction of lithium, due to the charge balance, the following equation must be verified:

$$
\left[\mathrm{C}_{2} \mathrm{mim}^{+}\right]_{\mathrm{aq}, \mathrm{ext}}+\left[\mathrm{Tf}_{2} \mathrm{~N}^{-}\right]_{\mathrm{org}, \text { ext }}=\left[\mathrm{Li}^{+}\right]_{\mathrm{org}}=\left[\mathrm{Li}^{+}\right]_{\mathrm{aq}, \text { init }}-\left[\mathrm{Li}^{+}\right]_{\mathrm{aq}}
$$

The subscripts "aq,ext" and "aq,sol" are used to make the difference between $\mathrm{C}_{2} \mathrm{mim}^{+}$aq,ext concentration found due to the exchange with $\mathrm{Li}^{+}$, and the concentration found due to the IL solubility $\left(\left[\mathrm{C}_{2} \mathrm{mim}^{+}\right]_{\mathrm{aq}, \mathrm{sol}}\right)$ in the aqueous phase according to the following reaction:

$$
\left[\mathrm{C}_{2} \operatorname{mim}\right]\left[\mathrm{Tf}_{2} \mathrm{~N}\right]_{\text {org }} \rightleftarrows \mathrm{C}_{2} \mathrm{mim}_{\text {aq,sol }}^{+}+\mathrm{Tf}_{2} \mathrm{~N}^{-} \text {aq,sol }
$$

The global $\left[\mathrm{C}_{2} \mathrm{mim}^{+}\right]_{\mathrm{aq}}$ and $\left[\mathrm{Tf}_{2} \mathrm{~N}^{-}\right]_{\mathrm{aq}}$ aqueous concentrations will be as follows:

$$
\left[\mathrm{C}_{2} \mathrm{mim}^{+}\right]_{\mathrm{aq}}=\left[\mathrm{C}_{2} \mathrm{mim}^{+}\right]_{\mathrm{aq}, \mathrm{sol}}+\left[\mathrm{C}_{2} \mathrm{mim}^{+}\right]_{\mathrm{aq}, \mathrm{ext}}
$$

And similarly:

$$
\left[\mathrm{Tf}_{2} \mathrm{~N}^{-}\right]_{\mathrm{aq}}=\left[\mathrm{Tf}_{2} \mathrm{~N}^{-}\right]_{\mathrm{aq}, \mathrm{sol}}-\left[\mathrm{Tf}_{2} \mathrm{~N}^{-}\right]_{\text {org,ext }}
$$

Where $\left[\mathrm{Tf}_{2} \mathrm{~N}^{-}\right]_{\text {ext }}$ is the IL anion concentration transferred to the organic phase under the 
form of an ion pair with the lithium ion. The IL solubility corresponding to $\left[\mathrm{C}_{2} \mathrm{mim}^{+}\right]_{\mathrm{aq}, \text { sol }}$ and $\left[\mathrm{Tf}_{2} \mathrm{~N}^{-}\right]_{\text {aq,sol }}$ concentrations, was measured at equilibrium using aqueous phases without lithium (first point in Table 1). These values were used to calculate $\left[\mathrm{C}_{2} \mathrm{mim}^{+}\right]_{\mathrm{aq} \text {,ext }}$ and $\left[\mathrm{Tf}_{2} \mathrm{~N}^{-}\right]_{\text {ext }}$ as follows:

$$
\begin{gathered}
{\left[\mathrm{C}_{2} \mathrm{mim}^{+}\right]_{\mathrm{aq}, \mathrm{ext}}=\left[\mathrm{C}_{2} \mathrm{mim}^{+}\right]_{\mathrm{aq}}-\left[\mathrm{C}_{2} \mathrm{mim}^{+}\right]_{\mathrm{aq}, \mathrm{sol}}} \\
{\left[\mathrm{Tf}_{2} \mathrm{~N}^{-}\right]_{\text {org,ext }}=\left[\mathrm{Tf}_{2} \mathrm{~N}^{-}\right]_{\mathrm{aq}, \mathrm{sol}}-\left[\mathrm{Tf}_{2} \mathrm{~N}^{-}\right]_{\mathrm{aq}}}
\end{gathered}
$$

$\left[\mathrm{C}_{2} \mathrm{mim}^{+}\right]_{\mathrm{aq}},\left[\mathrm{Tf}_{2} \mathrm{~N}^{-}\right]_{\mathrm{aq}}$ are values that were measured at equilibrium for every sample as a function of the initial concentration of lithium in the aqueous phase. All data are presented in Table 1, where we can see that the equation (8) is approximately verified. Hamamoto and coworkers [28] used the same approach, based on the solubility measurements and balance charge of the system, in order to find the laws that govern the extraction of cations from water to ILs without chelating agents. They studied the extraction of mono- and divalent alkylpyridinium cations from aqueous solutions into ten hydrophobic ILs of 1-butyl-3methylimidazolium-based or bis (trifluoromethanesulfonyl) amide-based salts. They found that the extraction is going through two different mechanisms, an ion exchange with the IL constituent cation and an ion pair transfers with the IL anion.

The extraction equilibrium constants $\left(K_{1}, K_{2}\right)$ and the distribution ratios $\left(D_{1}, D_{2}\right)$ referring to the reactions (6) and (7) respectively, can be written as:

$$
\begin{gathered}
K_{1}=\frac{\left[\mathrm{Li} \cdot \mathrm{nTBP}^{+}\right]_{\mathrm{org} \cdot} \cdot\left[\mathrm{C}_{2} \mathrm{mim}^{+}\right]_{\mathrm{aq}}}{\left[\mathrm{Li}^{+}\right]_{\mathrm{aq}} \times[\mathrm{TBP}]_{\mathrm{org}}^{\mathrm{n}} \cdot\left[\mathrm{C}_{2} \mathrm{mim}^{+}\right]_{\mathrm{org}}} \\
K_{2}=\frac{\left[\mathrm{LiTf}_{2} \mathrm{~N} \cdot \mathrm{mTBP}\right]_{\mathrm{org}}}{[\mathrm{Li}]_{\mathrm{aq}} \cdot[\mathrm{TBP}]_{\mathrm{org}}^{\mathrm{m}} \cdot\left[\mathrm{Tf}_{2} \mathrm{~N}^{-}\right]_{\mathrm{aq}}} \\
D_{1}=\frac{[\mathrm{Li}]_{\mathrm{org}}}{[\mathrm{Li}]_{\mathrm{aq}}}=\frac{\left[\mathrm{Li} \cdot \mathrm{nTBP}{ }^{+}\right]_{\mathrm{org}}}{\left[\mathrm{Li}^{+}\right]_{\mathrm{aq}}}=K_{1} \cdot \frac{[\mathrm{TBP}]_{\mathrm{org}}^{\mathrm{n}} \cdot\left[\mathrm{C}_{2} \mathrm{mim}^{+}\right]_{\mathrm{org}}}{\left[\mathrm{C}_{2} \mathrm{mim}^{+}\right]_{\mathrm{aq}, \mathrm{ext}}}
\end{gathered}
$$




$$
D_{2}=\frac{[\mathrm{Li}]_{\mathrm{org}}}{[\mathrm{Li}]_{\mathrm{aq}}}=\frac{\left[\mathrm{LiTf}_{2} \mathrm{~N} \cdot \mathrm{mTBP}\right]_{\mathrm{org}}}{\left[\mathrm{Li}^{+}\right]_{\mathrm{aq}}}=K_{2} \cdot[\mathrm{TBP}]_{\mathrm{org}}^{\mathrm{m}} \cdot\left[\mathrm{Tf}_{2} \mathrm{~N}^{-}\right]_{\mathrm{aq}}
$$

Based on the data presented on the Table 1, we can suppose that:

$\left[\mathrm{LiTf}_{2} \mathrm{~N} \cdot \mathrm{mTBP}\right]_{\text {org }}=\left[\mathrm{Tf}_{2} \mathrm{~N}^{-}\right]_{\mathrm{ext}}$ and $\left[\mathrm{Li} \cdot \mathrm{nTBP}^{+}\right]_{\text {org }}=\left[\mathrm{C}_{2} \mathrm{mim}^{+}\right]_{\mathrm{aq}, \mathrm{ext}}$

Based on the previous assumption, it is possible to determine the equilibrium constant for each reaction involved in the extraction of lithium, and the number of TBP molecules in the lithium ion coordination sphere for both mechanisms. First, an isotherm of extraction is plotted for each reaction based on experimental data. Then, a theoretical curve is traced and adjusted to the experimental curve.

The equation of each extraction isotherm can be written as follows:

Cation exchange:

$$
\left[\mathrm{Li}^{+}\right]_{\text {org }}=\left[\mathrm{Li} \cdot \mathrm{nTBP}^{+}\right]_{\text {org }}=\frac{\mathrm{K}_{1} \cdot[\mathrm{TBP}]^{\mathrm{n}}{ }_{\text {org }} \cdot\left[\mathrm{C}_{2} \mathrm{mim}^{+}\right]_{\text {org }, \mathrm{eq}} \cdot\left[\mathrm{Li}^{+}\right]_{\mathrm{aq}}}{\left[\mathrm{C}_{2} \mathrm{mim}^{+}\right]_{\mathrm{aq}}}
$$

Ion pair transfer:

$$
\left[\mathrm{Li}^{+}\right]_{\text {org }}=\left[\mathrm{LiTf}_{2} \mathrm{~N} \cdot \mathrm{mTBP}\right]_{\text {org }}=\mathrm{K}_{2} \cdot[\mathrm{TBP}]_{\mathrm{org}}^{\mathrm{m}} \cdot\left[\mathrm{Tf}_{2} \mathrm{~N}^{-}\right]_{\mathrm{aq}} \cdot\left[\mathrm{Li}^{+}\right]_{\mathrm{aq}}
$$

Where $\left[\mathrm{C}_{2} \mathrm{mim}^{+}\right]_{\text {org,eq }}=\left[\mathrm{C}_{2} \mathrm{mim}^{+}\right]_{\text {org, init }}-\left[\mathrm{C}_{2} \mathrm{mim}^{+}\right]_{\mathrm{aq}}$ and $[\mathrm{TBP}]_{\text {org }}=[\mathrm{TBP}]_{\text {org,init }}-$ $(0.67 \times \mathrm{n}+0.33 \times \mathrm{m}) \cdot\left[\mathrm{Li}^{+}\right]_{\mathrm{org}}$, because, from the Table 1 , we can supposed that two-thirds of the lithium in the organic phase is extracted by cationic exchange $\left(\left[\mathrm{C}_{2} \mathrm{mim}^{+}\right]_{\mathrm{aq}, \mathrm{ext}}=\right.$ $\left.\frac{2}{3}\left(\left[\mathrm{Li}^{+}\right]_{\mathrm{org}}\right)\right)$, while the other one-third is extracted by ion pair extraction $\left(\left[\mathrm{Tf}_{2} \mathrm{~N}^{-}\right]_{\text {ext }}=\right.$ $\left.\frac{1}{3}\left(\left[\mathrm{Li}^{+}\right]_{\text {org }}\right)\right)$

It can be seen from Figure 8 that the calculated and the experimental data are in good agreement. The equilibrium constants $\left(\mathrm{K}_{1}\right.$ and $\left.\mathrm{K}_{2}\right)$ and the stoichiometric coefficients (n and m) retained are values presented in Table 2. There are around 3 and 4 molecules of TBP 
coordinated to $\mathrm{Li}^{+}$ion, forming two complexes by two different mechanisms, the cation exchange and the ion pair transfer, respectively. Taking into account the small size of lithium, the ligand to metal ratios found could be considered high, but in the same time, it might be reasonable, considering that the lithium ion is usually highly coordinated [29]. Gao et al. in two different studies, proposed $2 \mathrm{LiCl}$. 3TIBP, and Li. $2 \mathrm{TIBP}^{+}$as structural formulas of lithium complexes. Shi et al, proposed also two different complexes Li.2TIBP ${ }^{+}[10]$ and Li. $^{2}$ TIBP $^{+}$ [14] to extract one lithium ion. These results can also explain the low extraction efficiency in highly acidic media seen in Figure 4. Indeed, the high acidic medium favors the dissolution of $\mathrm{C}_{2} \mathrm{mim}^{+}$, thus shifting the equilibrium of extraction by cation exchange (equation (6)) in the opposite way. The high acidic medium decreases also the free $\mathrm{Tf}_{2} \mathrm{~N}^{-}$ions, therefore, the lithium extraction by ion pair transfer decreases. Dietz et al [30] studied the strontium transfer into room-temperature ionic liquids containing crown ethers, and he proposed only the ionexchange as mechanism, neglecting the ion pair transfer and postulating that if an extraction of a complex incorporating $\mathrm{Tf}_{2} \mathrm{~N}^{-}$counterions is indeed occurring, conditions that increase the aqueous concentration of the anion like higher acidity are expected to yield the highest distribution ratios. However, this is not the case because higher acidity doesn't increase the aqueous concentration of IL anion as can be seen in Figure $6 b$.

The global distribution ratio can be written in the following form:

$$
\mathrm{D}=\mathrm{D}_{1}+\mathrm{D}_{2}
$$

Thus, by using the equilibrium constants and stoichiometric values found in the previous part and the IL constituents concentrations presented in the figure 3, it is possible to develop a mathematical model to predict the global distribution ratio of lithium as a function of the TBP concentration. 


$$
\begin{gathered}
\mathrm{D}=\mathrm{K}_{1} \cdot \frac{[\mathrm{TBP}]_{\mathrm{org}}^{\mathrm{n}} \cdot\left[\mathrm{C}_{2} \mathrm{mim}^{+}\right]_{\mathrm{org}}}{\left[\mathrm{C}_{2} \mathrm{mim}^{+}\right]_{\mathrm{aq}}}+\mathrm{K}_{2} \cdot[\mathrm{TBP}]_{\mathrm{org}}^{\mathrm{m}} \cdot\left[\mathrm{Tf}_{2} \mathrm{~N}^{-}\right]_{\mathrm{aq}} \\
\mathrm{D}=0.01 \times \frac{[\mathrm{TBP}]_{\mathrm{org}}^{3} \cdot\left[\mathrm{C}_{2} \mathrm{mim}^{+}\right]_{\mathrm{org}}}{\left[\mathrm{C}_{2} \mathrm{mim}^{+}\right]_{\mathrm{aq}}}+3.30 \times[\mathrm{TBP}]_{\mathrm{org}}^{4} \cdot\left[\mathrm{Tf}_{2} \mathrm{~N}^{-}\right]_{\mathrm{aq}}
\end{gathered}
$$

$[\mathrm{TBP}]_{\text {org }}$, is the free TBP content at equilibrium in the organic phase. It can be considered equal to the TBP initial concentration, given that the initial lithium concentration is much lower compared to it. Thus, the global distribution of lithium was calculated using the equation (22) and compared to experimental results (Figure 2). At low initial TBP concentration ( $<50$ vol. $\%)$, good agreement is observed between calculated and experimental D. At high TBP concentration, high deviations are observed. This is probably related to the variations of the IL constituents concentrations at high TBP concentration, or due to change of the coordination number at high TBP concentration or the formation of TBP aggregates. This is because the coordination numbers used for calculations were found at 40 vol.\% of TBP concentration. It is known also that TBP can form aggregates in applied separations, which lead sometimes to the formation of a third phase [31, 32].

\section{Extraction of Lithium using $\mathrm{Tf}_{2} \mathrm{~N}^{-}$as Counter-ion}

It is now well recognized and that the ILs are not inert solvents and that they are involved in the extraction process of metallic ions, as demonstrated above. Thus, we decided to study the behavior of lithium in an aqueous phase containing $\operatorname{LiTf}_{2} \mathrm{~N}$ salt contacted with two different organic phase composed of: $\mathrm{TBP} / 1$-octanol and $\mathrm{TBP} /\left[\mathrm{C}_{8} \mathrm{mim}\right]\left[\mathrm{Tf}_{2} \mathrm{~N}\right]$ (Figure 10a). $\left[\mathrm{C}_{8} \mathrm{mim}\right]\left[\mathrm{Tf}_{2} \mathrm{~N}\right]$ is an imidazolium-based IL with an alkyl chain longer than that of $\left[\mathrm{C}_{2} \operatorname{mim}\right]\left[\mathrm{Tf}_{2} \mathrm{~N}\right]$ which makes it more hydrophobic. The low solubility of $\left[\mathrm{C}_{8} \mathrm{mim}\right]\left[\mathrm{Tf}_{2} \mathrm{~N}\right]$ in aqueous phases prohibits the extraction of lithium by cation exchange. The metal by IL cation extraction leads to the loss of the IL and the contamination of the aqueous phase. Gao et al. studied the effect of the alkyl chain length from $\mathrm{C}_{4}$ to $\mathrm{C}_{9}$ in $\left[\mathrm{C}_{\mathrm{n}} \mathrm{mim}\right]\left[\mathrm{PF}_{6}\right]$, on the extraction 
of lithium using TIBP mixed with kerosene. They found that the lithium ion extraction decreases significantly when increasing the alkyl chain length of the IL cation. From the Figure 10a, it appears that whatever diluent used, firstly, the presence of $\mathrm{Tf}_{2} \mathrm{~N}^{-}$anions in aqueous solution leads to an enhancement of lithium ion extraction with TBP. Secondly, the distribution ratio of lithium increases as the TBP concentration in the extraction system increases. The lithium extraction efficiency is in the following order: 1-octanol $>\left[\mathrm{C}_{8} \mathrm{mim}\right]\left[\mathrm{Tf}_{2} \mathrm{~N}\right]$. This is probably because the lithium complex extracted with TBP is more soluble in 1-octanol than in $\left[\mathrm{C}_{8} \mathrm{mim}\right]\left[\mathrm{Tf}_{2} \mathrm{~N}\right]$. It is important to remember that $\mathrm{TBP} / 1$-octanol system has not been able to extract lithium when $\mathrm{Cl}^{-}$was used as counter-ion (Figure 2).

The ion pair transfer (equation (7)) seems to be the only mechanism by which lithium ions were extracted in this system. Taking the logarithm of both sides of the extraction constant equation (17), the following equation is obtained:

$$
\log D=m \cdot \log [\mathrm{TBP}]_{\text {org }}+\log \left[\mathrm{Tf}_{2} \mathrm{~N}^{-}\right]_{\mathrm{aq}}+\log K
$$

Considering that $\left[\mathrm{Tf}_{2} \mathrm{~N}^{-}\right]_{\mathrm{aq}}=[\mathrm{Li}]_{\mathrm{aq}}$, the equation (23) can be written as follows:

$$
\log D-\log [\mathrm{Li}]_{\mathrm{aq}}=m \cdot \log [\mathrm{TBP}]_{\text {org }}+\log K
$$

$[\mathrm{TBP}]_{\text {org }}$ is the free TBP content at equilibrium in the organic phase. It can be considered equal to the TBP initial concentration, given that the initial lithium concentration is much lower compared to it. $\left(\log D-\log [\mathrm{Li}]_{\mathrm{aq}}\right)$ for the two diluents plotted as a function of $\log [\mathrm{TBP}]_{\text {org }}$, can be seen in Figure 10b. Results show that the diluent affects the coordination number (m), and that this coordination number increases at high TBP concentrations. In the case of $\mathrm{TBP} /\left[\mathrm{C}_{8} \mathrm{mim}\right]\left[\mathrm{Tf}_{2} \mathrm{~N}\right]$, a slope of 4 at $\mathrm{TBP}$ concentrations below 60 vol.\% indicates that 1:4 (a lithium ion to four TBP molecules) complexes are formed, while, at high TBP concentrations a slope of 8 indicates that probably aggregates are formed. This supports our 
hypothesis previously issued to explain the poor agreement between the calculated and experimental D at high TBP concentration seen in Figure 9.

The 'critical' concentration at which this change of stoichiometry happens, change from one diluent to another. In the case of TBP/1-octanol, 1:3 complexes are formed bellow 40 vol.\% of TBP. In the system $\mathrm{LiCl} / \mathrm{HCl} / / \mathrm{TBP} /\left[\mathrm{C}_{2} \operatorname{mim}\right]\left[\mathrm{Tf}_{2} \mathrm{~N}\right]$, from the Figure 9 , this 'critical' concentration is probably around 50 vol.\% of TBP.

By using the equation (21) and varying $\mathrm{n}$ and $\mathrm{m}$, we tried to verify if we can obtain a good agreement between the calculated and experimental D at high TBP concentration. As seen in Figure 11, it is possible to obtain a much better agreement between calculated and experimental $\mathrm{D}$ than that observed previously. The stoichiometric values that show the best agreement are $\mathrm{n}=4$ and $\mathrm{m}=4$ for 60 vol. $\%<\mathrm{TBP}<80$ vol. $\%$ and $\mathrm{n}=4.5$ and $\mathrm{m}=5$ for TBP $>80$ vol.\%.

\section{Conclusion}

In this work, it was confirmed that TBP can extract efficiently lithium from hydrochloric or nitric acid media, when mixed with $\left[\mathrm{C}_{2} \operatorname{mim}\right]\left[\mathrm{Tf}_{2} \mathrm{~N}\right]$. Increasing the acidity of the aqueous solution decreases the extraction efficiency. Using analysis based on measurements of IL constituents concentrations in aqueous phases, two mechanisms of the lithium extraction were proposed. Each one involves one IL ion. The IL cation $\left(\mathrm{C}_{2} \mathrm{mim}^{+}\right)$substitute $\mathrm{Li}^{+}$in the aqueous phase, and the IL anion $\left(\mathrm{Tf}_{2} \mathrm{~N}^{-}\right)$initially dissolved in the aqueous phase, is backtransferred to the organic phase with the TBP- $\mathrm{Li}^{+}$complex. The role of IL constituents is therefore to ensure the electro-neutrality of the system since TBP is a neutral extractant. It was also evidenced that TBP can extract lithium even when diluted in a molecular diluent (1octanol), in a highly hydrophobic IL $\left(\left[\mathrm{C}_{8} \mathrm{mim}\right]\left[\mathrm{Tf}_{2} \mathrm{~N}\right]\right)$ but only if $\mathrm{Tf}_{2} \mathrm{~N}^{-}$is used as counterion. This is due to the high hydrophobicity of this anion. These results are a proof that complex incorporating $\mathrm{Tf}_{2} \mathrm{~N}^{-}$is indeed occurring in the $\mathrm{TBP} /\left[\left[\mathrm{C}_{2} \mathrm{mim}\right]\left[\mathrm{Tf}_{2} \mathrm{~N}\right]\right.$ system. 
Industrially speaking, the system of $\mathrm{TBP} /\left[\mathrm{C}_{2} \mathrm{mim}\right]\left[\mathrm{Tf}_{2} \mathrm{~N}\right]$ is not attractive for the extraction of lithium, because of the partitioning of the IL cation into the aqueous phase and the need of using high TBP concentrations to reach high lithium extraction efficiency. However, the use of TBP diluted in $\left[\mathrm{C}_{8} \mathrm{mim}\right]\left[\mathrm{Tf}_{2} \mathrm{~N}\right]$ with the presence of $\mathrm{Tf}_{2} \mathrm{~N}^{-}$in the aqueous phase has shown satisfying extraction efficiency for lithium. In such a system, it is unnecessary to sacrifice IL cations. The complete and detailed understanding of the mechanism(s) of extraction in IL media could help to improve both the extraction efficiency and the selectivity for lithium using solvent extraction. The design of a lithium selective solvent extraction process could be inspired by the unusual extraction efficiency observed in IL media. However, future work should be focused on the use of cheaper and more environmentally friendly products.

\section{Acknowledgements}

This work is funded by National Institute of Nuclear and Physic of Particles -IN2P3-CNRS and Grand Est region, France (PhD Fellowship of AM). The authors gratefully thank Maurice Coppe (Institute of Chemistry, University of Strasbourg, France) for the NMR measurements, and Pascale Ronot and Islah El-masoudi (Pluridisciplinary Institute Hubert Curien (IPHC) Strasbourg, France) for the ICP-OES measurements.

\section{References}

[1] Swain, B. Separation and Purification of Lithium by Solvent Extraction and Supported Liquid Membrane, Analysis of Their Mechanism: A Review. Journal of Chemical Technology \& Biotechnology, 2016, 91 (10), 2549-2562. https://doi.org/10.1002/jctb.4976.

[2] Speirs, J.; Contestabile, M.; Houari, Y.; Gross, R. The Future of Lithium Availability for Electric Vehicle Batteries. Renewable and Sustainable Energy Reviews, 2014, 35, 183-193. https://doi.org/10.1016/j.rser.2014.04.018.

[3] Martin, G.; Rentsch, L.; Höck, M.; Bertau, M. Lithium Market Research - Global Supply, Future Demand and Price Development. Energy Storage Materials, 2017, 6, 171-179. https://doi.org/10.1016/j.ensm.2016.11.004. 
[4] G. Huddleston, J.; D. Willauer, H.; P. Swatloski, R.; E. Visser, A.; D. Rogers, R. Room Temperature Ionic Liquids as Novel Media for 'Clean' Liquid-Liquid Extraction. Chemical Communications, 1998, 0 (16), 1765-1766. https://doi.org/10.1039/A803999B.

[5] Wang, K.; Adidharma, H.; Radosz, M.; Wan, P.; Xu, X.; Russell, C. K.; Tian, H.; Fan, M.; Yu, J. Recovery of Rare Earth Elements with Ionic Liquids. Green Chem., 2017, 19 (19), 4469-4493. https://doi.org/10.1039/C7GC02141K.

[6] Zhao, X.; Wu, H.; Duan, M.; Hao, X.; Yang, Q.; Zhang, Q.; Huang, X. Liquid-Liquid Extraction of Lithium from Aqueous Solution Using Novel Ionic Liquid Extractants via COSMO-RS and Experiments. Fluid Phase Equilibria, 2018, 459, 129-137. https://doi.org/10.1016/j.fluid.2017.11.038.

[7] Shi, C.; Jing, Y.; Xiao, J.; Wang, X.; Jia, Y. Liquid-Liquid Extraction of Lithium Using Novel Phosphonium Ionic Liquid as an Extractant. Hydrometallurgy, 2017, 169, 314-320. https://doi.org/10.1016/j.hydromet.2017.02.015.

[8] Shi, C.; Jing, Y.; Xiao, J.; Wang, X.; Yao, Y.; Jia, Y. Solvent Extraction of Lithium from Aqueous Solution Using Non-Fluorinated Functionalized Ionic Liquids as Extraction Agents. Separation and Purification Technology, 2017, 172, 473-479. https://doi.org/10.1016/j.seppur.2016.08.034.

[9] Shi, C.; Jia, Y.; Zhang, C.; Liu, H.; Jing, Y. Extraction of Lithium from Salt Lake Brine Using Room Temperature Ionic Liquid in Tributyl Phosphate. Fusion Engineering and Design, 2015, 90, 1-6. https://doi.org/10.1016/j.fusengdes.2014.09.021.

[10] Shi, C.; Duan, D.; Jia, Y.; Jing, Y. A Highly Efficient Solvent System Containing Ionic Liquid in Tributyl Phosphate for Lithium Ion Extraction. Journal of Molecular Liquids, 2014, 200, 191-195. https://doi.org/10.1016/j.molliq.2014.10.004.

[11] Shi, C.; Jia, Y.; Xie, S.; Qiu, F.; Jing, Y. Extraction of Lithium Ion Using Ionic Liquids Dissolved in Tributyl Phosphate.

[12] Sekimoto, T.; Nishihama, S.; Yoshizuka, K. Extraction of Lithium from Salt Lake Brine with Tributyl Phosphate and an Ionic Liquid. SERDJ, 2018, 25 (2), 117-123. https://doi.org/10.15261/serdj.25.117.

[13] Shi, C.; Jing, Y.; Jia, Y. Tri-n-Butyl Phosphate-Ionic Liquid Mixtures for Li+ Extraction from Mg2+-Containing Brines at 303-343 K. Russ. J. Phys. Chem., 2017, 91 (4), 692-696. https://doi.org/10.1134/S0036024417040033. 
[14] Shi, C.; Jing, Y.; Jia, Y. Solvent Extraction of Lithium Ions by Tri-n-Butyl Phosphate Using a Room Temperature Ionic Liquid. Journal of Molecular Liquids, 2016, 215, 640-646. https://doi.org/10.1016/j.molliq.2016.01.025.

[15] Wang, X.; Jing, Y.; Liu, H.; Yao, Y.; Shi, C.; Xiao, J.; Wang, S.; Jia, Y. Extraction of Lithium from Salt Lake Brines by Bis[(Trifluoromethyl)Sulfonyl]Imide-Based Ionic Liquids. Chemical Physics Letters, 2018, 707, 8-12. https://doi.org/10.1016/j.cplett.2018.07.030.

[16] Gao, D.; Yu, X.; Guo, Y.; Wang, S.; Liu, M.; Deng, T.; Chen, Y.; Belzile, N. Extraction of Lithium from Salt Lake Brine with Triisobutyl Phosphate in Ionic Liquid and Kerosene. Chem. Res. Chin. Univ., 2015, 31 (4), 621-626. https://doi.org/10.1007/s40242-015-4376-Z.

[17] Gao, D.; Guo, Y.; Yu, X.; Wang, S.; Deng, T. Extracting Lithium from the High Concentration Ratio of Magnesium and Lithium Brine Using Imidazolium-Based Ionic Liquids with Varying Alkyl Chain Lengths. JOURNAL OF CHEMICAL ENGINEERING OF JAPAN, 2018, 49 (2), 104-110. https://doi.org/10.1252/jcej.15we046.

[18] Billard, I. Chapter 256 - Ionic Liquids: New Hopes for Efficient Lanthanide/Actinide Extraction and Separation? In Handbook on the Physics and Chemistry of Rare Earths; Bünzli, J.-C. G., Pecharsky, V. K., Eds.; Including Actinides; Elsevier, 2013; Vol. 43, pp 213-273. https://doi.org/10.1016/B978-0-444-59536-2.00003-9.

[19] Malz, F.; Jancke, H. Validation of Quantitative NMR. J Pharm Biomed Anal, 2005, 38 (5), 813-823. https://doi.org/10.1016/j.jpba.2005.01.043.

[20] Montalbán, M. G.; Collado-González; Trigo; DíazBaños, F. G. Experimental Measurements of Octanol-Water Partition Coefficients of Ionic Liquids; 2015.

[21] Mazan, V.; Billard, I.; Papaiconomou, N. Experimental Connections between Aqueous-Aqueous and Aqueous-Ionic Liquid Biphasic Systems. RSC Adv., 2014, 4 (26), 13371-13384. https://doi.org/10.1039/C4RA00645C.

[22] Rickert, P. G.; Stepinski, D. C.; Rausch, D. J.; Bergeron, R. M.; Jakab, S.; Dietz, M. L. Solute-Induced Dissolution of Hydrophobic Ionic Liquids in Water. Talanta, 2007, 72 (1), 315-320. https://doi.org/10.1016/j.talanta.2006.10.033.

[23] Gaillard, D. C.; Boltoeva, M.; Billard, I.; Georg, S.; Mazan, V.; Ouadi, A.; Ternova, D.; Hennig, C. Insights into the Mechanism of Extraction of Uranium (VI) from Nitric 
Acid Solution into an Ionic Liquid by Using Tri-n-Butyl Phosphate. Chemphyschem, 2015, 16 (12), 2653-2662. https://doi.org/10.1002/cphc.201500283.

[24] Mazan, V.; Boltoeva, M. Y.; Tereshatov, E. E.; Iii, C. M. F. Mutual Solubility of Water and Hydrophobic Ionic Liquids in the Presence of Hydrochloric Acid. RSC Adv., 2016, 6 (61), 56260-56270. https://doi.org/10.1039/C6RA06791C.

[25] Turanov, A. N.; Karandashev, V. K.; Baulin, V. E. Extraction of Alkaline Earth Metal Ions with TODGA in the Presence of Ionic Liquids. Solvent Extraction and Ion Exchange, 2010, 28 (3), 367-387. https://doi.org/10.1080/07366291003684238.

[26] Dupont, D.; Depuydt, D.; Binnemans, K. Overview of the Effect of Salts on Biphasic Ionic Liquid/Water Solvent Extraction Systems: Anion Exchange, Mutual Solubility, and Thermomorphic Properties. J. Phys. Chem. B, 2015, 119 (22), 6747-6757. https://doi.org/10.1021/acs.jpcb.5b02980.

[27] Neves, C. M. S. S.; Held, C.; Mohammad, S.; Schleinitz, M.; Coutinhoa, J. A. P.; Freire, M. G. Effect of Salts on the Solubility of Ionic Liquids in Water: Experimental and Electrolyte Perturbed-Chain Statistical Associating Fluid Theory. Phys Chem Chem Phys, 2015, 17 (47), 32044-32052. https://doi.org/10.1039/c5cp06166k.

[28] Hamamoto, T.; Okai, M.; Katsuta, S. The Laws Governing Ionic Liquid Extraction of Cations: Partition of 1-Ethylpyridinium Monocation and Paraquat Dication in Ionic Liquid/Water Biphasic Systems. J. Phys. Chem. B, 2015, 119 (20), 6317-6325. https://doi.org/10.1021/acs.jpcb.5b02923.

[29] Olsher, Uriel.; Izatt, R. M.; Bradshaw, J. S.; Dalley, N. Kent. Coordination Chemistry of Lithium Ion: A Crystal and Molecular Structure Review. Chem. Rev., 1991, 91 (2), 137-164. https://doi.org/10.1021/cr00002a003.

[30] Dietz, M. L.; Dzielawa, J. A.; Laszak, I.; Young, B. A.; Jensen, M. P. Influence of Solvent Structural Variations on the Mechanism of Facilitated Ion Transfer into Room-Temperature Ionic Liquids. Green Chem., 2003, 5 (6), 682-685. https://doi.org/10.1039/B310507P.

[31] Baldwin, A. G. Understanding Aggregation of Solvating Extractants in Applied Separations. Thesis, Colorado School of Mines. Arthur Lakes Library, 2018.

[32] Guilbaud, P.; Berthon, L.; Louisfrema, W.; Diat, O.; Zorz, N. Determination of the Structures of Uranyl-Tri-n-Butyl-Phosphate Aggregates by Coupling Experimental Results with Molecular Dynamic Simulations. Chemistry - A European Journal, 2017, 23 (65), 16660-16670. https://doi.org/10.1002/chem.201703967. 


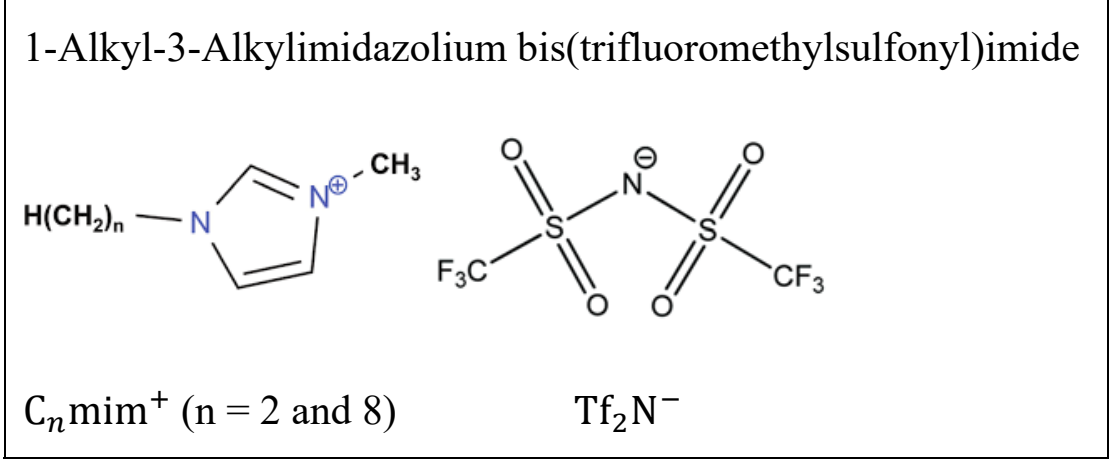

Figure 1. Chemical structure of imidazolium-based ionic liquids used in this study

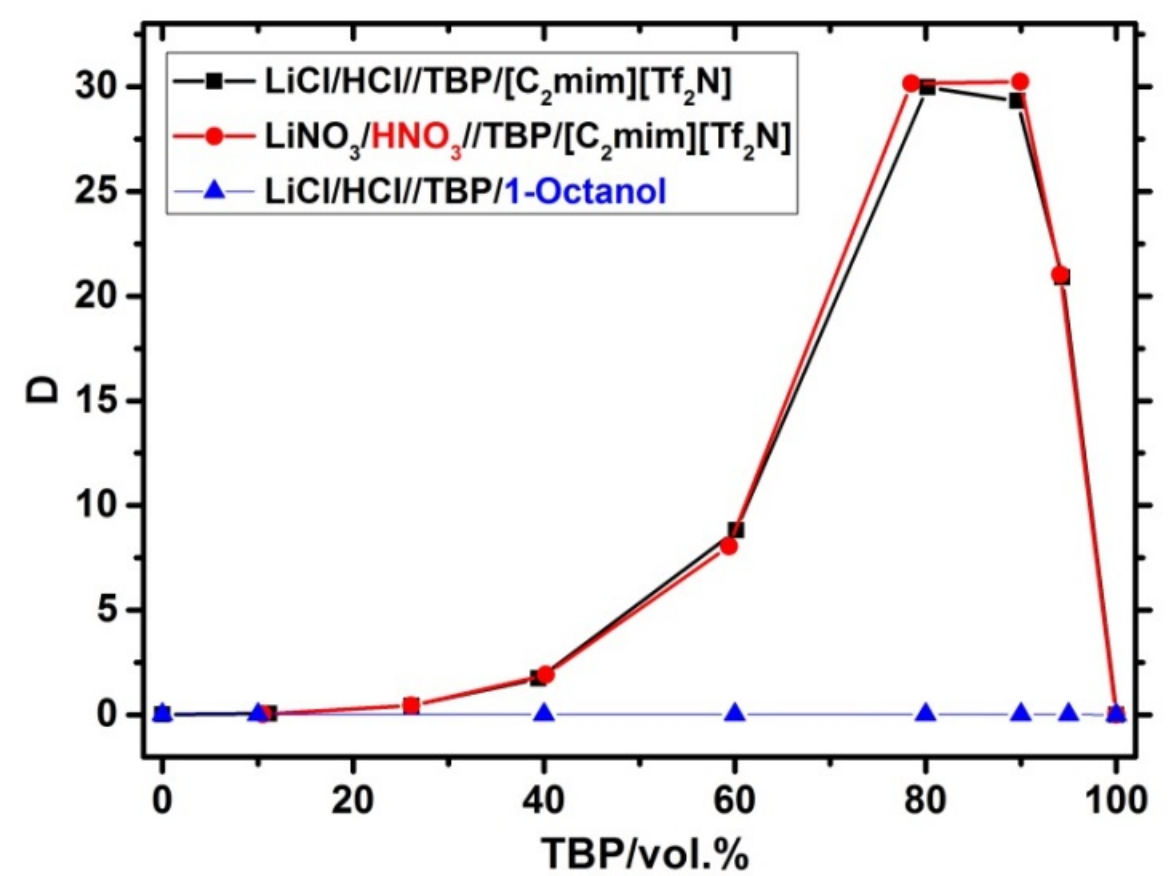

Figure 2. Effect of TBP volume concentration mixed with two diluents,

$\left(\left[\mathrm{C}_{2} \mathrm{mim}\right]\left[\mathrm{Tf}_{2} \mathrm{~N}\right]\right.$ and 1-octanol) on the lithium extraction from aqueous acidic solutions, $\mathrm{HCl}$ or $\mathrm{HNO}_{3} \cdot \mathrm{pH}_{\text {initial }}=2$ and $\left[\mathrm{Li}^{+}\right]_{\mathrm{aq}, \text { init }}=15.4 \pm 0.8$ mmol.L ${ }^{-1}$. 


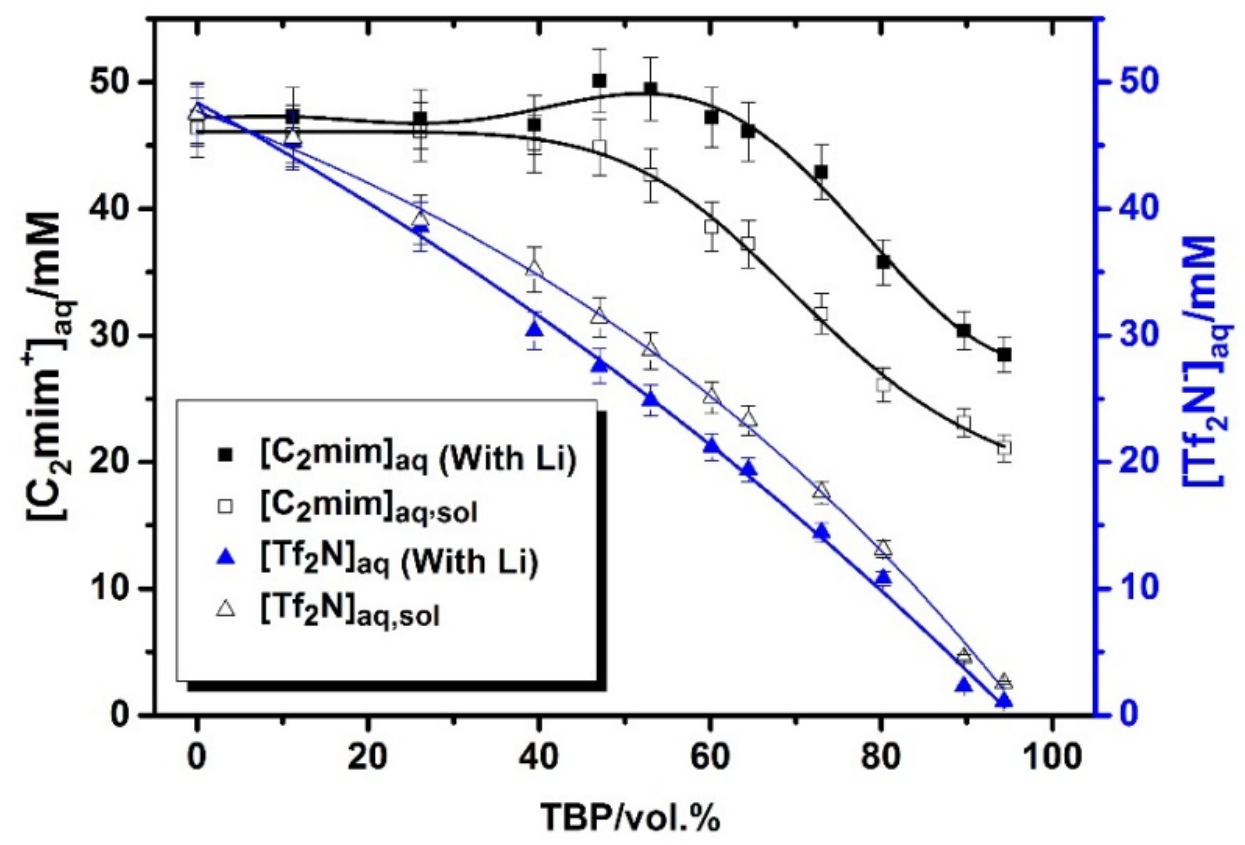

Figure 3. Equilibrium aqueous concentrations of IL ions $\left(\mathrm{C}_{2} \mathrm{mim}^{+}, \mathrm{Tf}_{2} \mathrm{~N}^{-}\right)$as a function of TBP volume concentration in $\left[\mathrm{C}_{2} \mathrm{mim}\right]\left[\mathrm{Tf}_{2} \mathrm{~N}\right]$ with and without lithium in the aqueous phase $\left(\mathrm{pH}_{\text {initial }}=2,\left[\mathrm{Li}^{+}\right]_{\mathrm{aq}, \text { init }}=15.4 \pm 0.8\right.$ or $\left.\left[\mathrm{Li}^{+}\right]_{\mathrm{aq}, \text { init }}=0.0 \mathrm{mmol} . \mathrm{L}^{-1}\right)$.

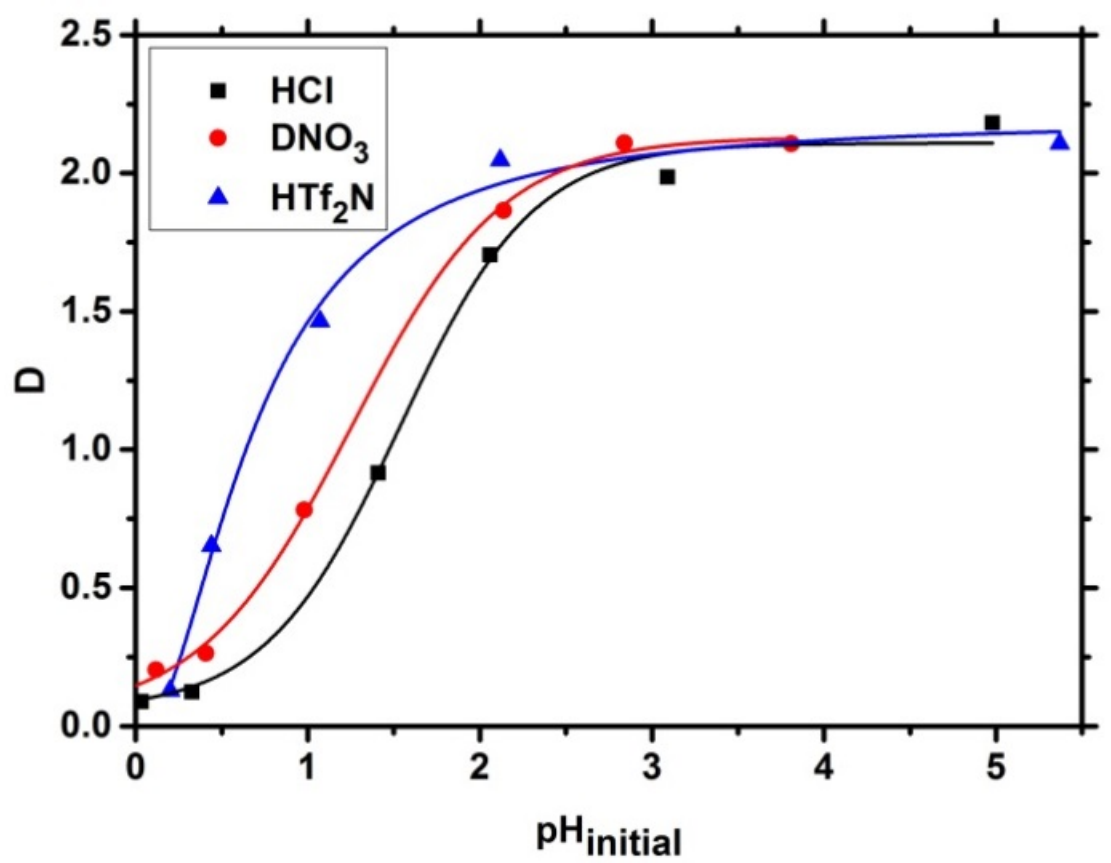

Figure 4. Effect of the initial aqueous $\mathrm{pH}$ of acidic solutions $\left(\mathrm{HCl}, \mathrm{DNO}_{3}\right.$ and $\left.\mathrm{HTf}_{2} \mathrm{~N}\right)$ on the extraction of lithium with 40 vol. $\% \mathrm{TBP} /\left[\mathrm{C}_{2} \mathrm{mim}\right]\left[\mathrm{Tf}_{2} \mathrm{~N}\right]$ mixture. Initial lithium concentration in all aqueous phases was $14 \pm 4$ mmol.L ${ }^{-1}$. 


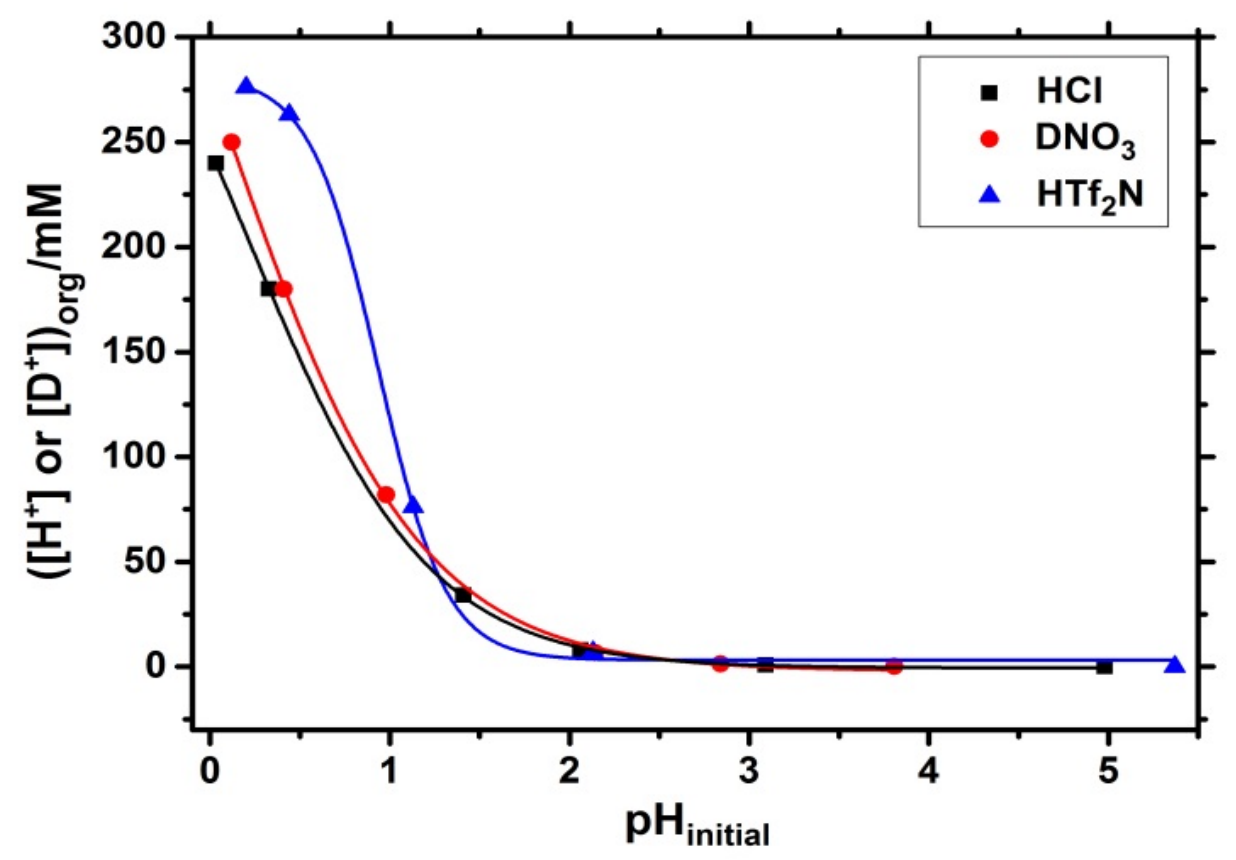

Figure 5. Proton concentration extracted to the organic phase as a function of the initial aqueous phase $\mathrm{pH}$. Organic phase: 40 vol. $\% \mathrm{TBP} /\left[\mathrm{C}_{2} \mathrm{mim}\right]\left[\mathrm{Tf}_{2} \mathrm{~N}\right]$.
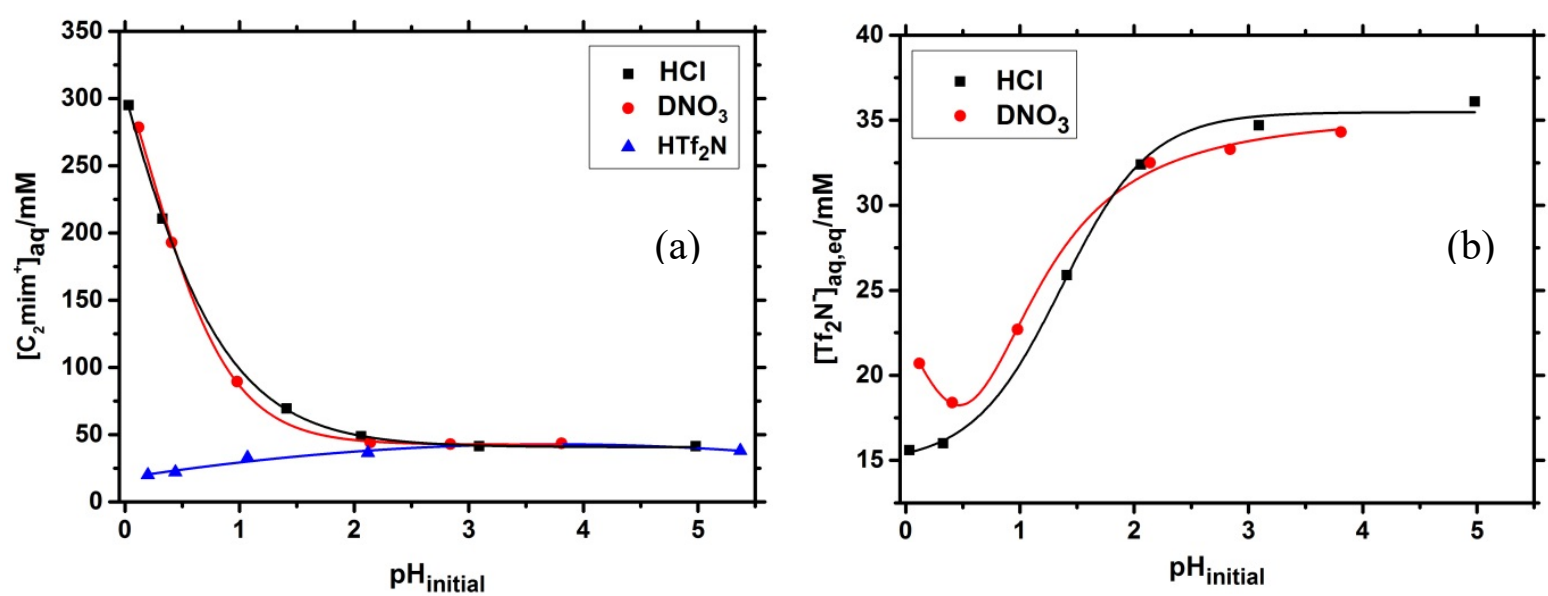

Figure 6. Equilibrium concentrations of $\left[\mathrm{C}_{2} \mathrm{mim}^{+}\right]$(a) and $[\mathrm{Tf} 2 \mathrm{~N}-]$ (b) in the aqueous solutions $\left(\mathrm{HCl}\right.$ and $\left.\mathrm{DNO}_{3}\right)$ as a function of the initial $\mathrm{pH}$. Organic phase: 40 vol.\% $\mathrm{TBP} /\left[\mathrm{C}_{2} \operatorname{mim}\right]\left[\mathrm{Tf}_{2} \mathrm{~N}\right]$. 

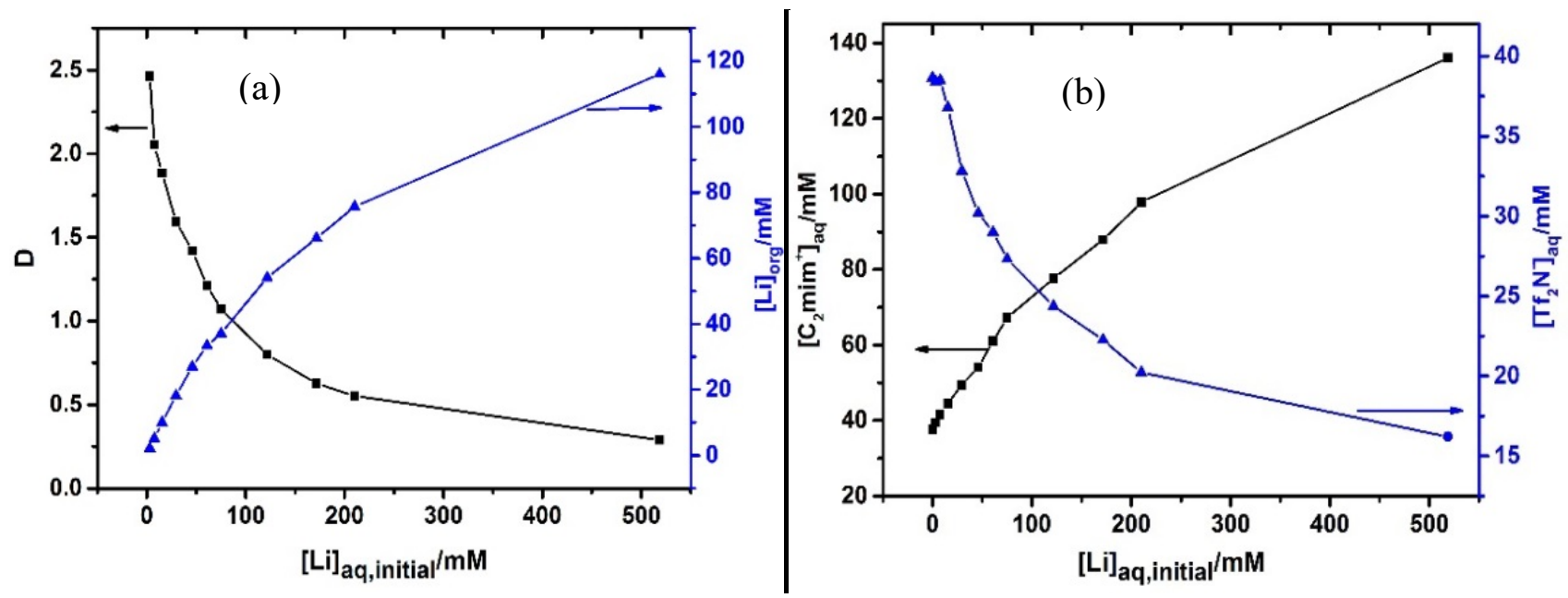

Figure 7. Effect of the initial lithium concentration in the aqueous phase on its extraction by 40 vol.\% TBP/ $\left[\mathrm{C}_{2} \mathrm{mim}\right]\left[\mathrm{Tf}_{2} \mathrm{~N}\right]$ : (a) Distribution ratio of $\mathrm{Li}$ ions and its concentration in the organic phase and (b) Equilibrium concentration of the IL constituents in aqueous solution. Aqueous phase: $\mathrm{LiCl} /$ Deionized water.

Table 1. Equilibrium concentration of lithium ions in the organic phase and of IL constituents $\left(\mathrm{C}_{2} \mathrm{mim}^{+}, \mathrm{Tf}_{2} \mathrm{~N}^{-}\right)$in aqueous phase as a function of the initial lithium ion concentration. Verification of the equation (8).

\begin{tabular}{|c|c|c|c|c|c|c|}
\hline $\begin{array}{l}{\left[\mathrm{Li}^{+}\right]_{\text {aq,init }}} \\
(\mathrm{mM})\end{array}$ & $\begin{array}{l}{\left[\mathrm{C}_{2} \mathrm{mim}^{+}\right]_{\mathrm{aq}}} \\
(\mathrm{mM})\end{array}$ & $\begin{array}{l}{\left[\mathrm{Tf}_{2} \mathrm{~N}^{-}\right]_{\mathrm{aq}}} \\
(\mathrm{mM})\end{array}$ & $\begin{array}{l}{\left[\mathrm{C}_{2} \operatorname{mim}^{+}\right]_{\mathrm{aq}, \mathrm{ex}}} \\
(\mathrm{mM})\end{array}$ & $\begin{array}{c}{\left[\mathrm{Tf}_{2} \mathrm{~N}^{-}\right]_{\text {org,ex }}} \\
(\mathrm{mM})\end{array}$ & $\begin{array}{l}{\left[\mathrm{C}_{2} \mathrm{mim}^{+}\right]_{\text {aq,ext }}} \\
+\left[\mathrm{Tf}_{2} \mathrm{~N}^{-}\right]_{\text {org,ext }} \\
(\mathrm{mM})\end{array}$ & $\begin{array}{l}{\left[\mathrm{Li}^{+}\right]_{\mathrm{org}}} \\
(\mathrm{mM})\end{array}$ \\
\hline 0 & $37.7 \pm 1.9$ & $38.7 \pm 1.9$ & - & - & - & 0 \\
\hline $3.12 \pm 0.16$ & $39.4 \pm 2.0$ & $38.4 \pm 1.9$ & $1.74 \pm 0.09$ & $0.24 \pm 0.01$ & $1.98 \pm 0.10$ & $2.13 \pm 0.11$ \\
\hline $7.66 \pm 0.38$ & $41.6 \pm 2.1$ & $37.9 \pm 1.9$ & $3.96 \pm 0.20$ & $0.82 \pm 0.04$ & $4.8 \pm 0.2$ & $5.2 \pm 0.3$ \\
\hline $15.3 \pm 0.8$ & $44.5 \pm 2.2$ & $36.8 \pm 1.8$ & $6.86 \pm 0.34$ & $1.9 \pm 0.1$ & $8.7 \pm 0.4$ & $10.0 \pm 0.5$ \\
\hline $29.6 \pm 1.5$ & $49.5 \pm 2.5$ & $32.8 \pm 1.6$ & $11.8 \pm 0.6$ & $5.8 \pm 0.3$ & $17.6 \pm 0.9$ & $18.2 \pm 0.9$ \\
\hline $46.0 \pm 2.3$ & $54.1 \pm 2.7$ & $30.2 \pm 1.5$ & $16.5 \pm 0.8$ & $8.5 \pm 0.4$ & $24.9 \pm 1.2$ & $27.0 \pm 1.4$ \\
\hline $61.0 \pm 3.1$ & $61.1 \pm 3.1$ & $29.0 \pm 1.5$ & $23.5 \pm 1.2$ & $9.7 \pm 0.5$ & $33.1 \pm 1.7$ & $33.4 \pm 1.7$ \\
\hline $75.0 \pm 3.8$ & $67.2 \pm 3.4$ & $27.3 \pm 1.4$ & $29.5 \pm 1.5$ & $11.3 \pm 0.6$ & $40.9 \pm 2.0$ & $37.1 \pm 1.9$ \\
\hline
\end{tabular}




\begin{tabular}{|l|l|l|l|l|l|l|}
\hline $122 \pm 6$ & $77.7 \pm 3.9$ & $24.4 \pm 1.2$ & $40.1 \pm 2.0$ & $14.3 \pm 0.7$ & $54.3 \pm 2.7$ & $54.1 \pm 2.7$ \\
\hline $172 \pm 8$ & $87.9 \pm 4.4$ & $22.3 \pm 1.1$ & $50.3 \pm 2.5$ & $16.4 \pm 0.8$ & $66.6 \pm 3.3$ & $66.1 \pm 3.3$ \\
\hline $210 \pm 10$ & $97.9 \pm 4.9$ & $20.2 \pm 1.0$ & $60.2 \pm 3.0$ & $18.4 \pm 0.9$ & $78.6 \pm 3.9$ & $75.7 \pm 3.8$ \\
\hline $518 \pm 26$ & $136 \pm 6.8$ & $16.2 \pm 0.8$ & $98.5 \pm 4.9$ & $22.4 \pm 1.1$ & $121 \pm 6$ & $116 \pm 6$ \\
\hline
\end{tabular}

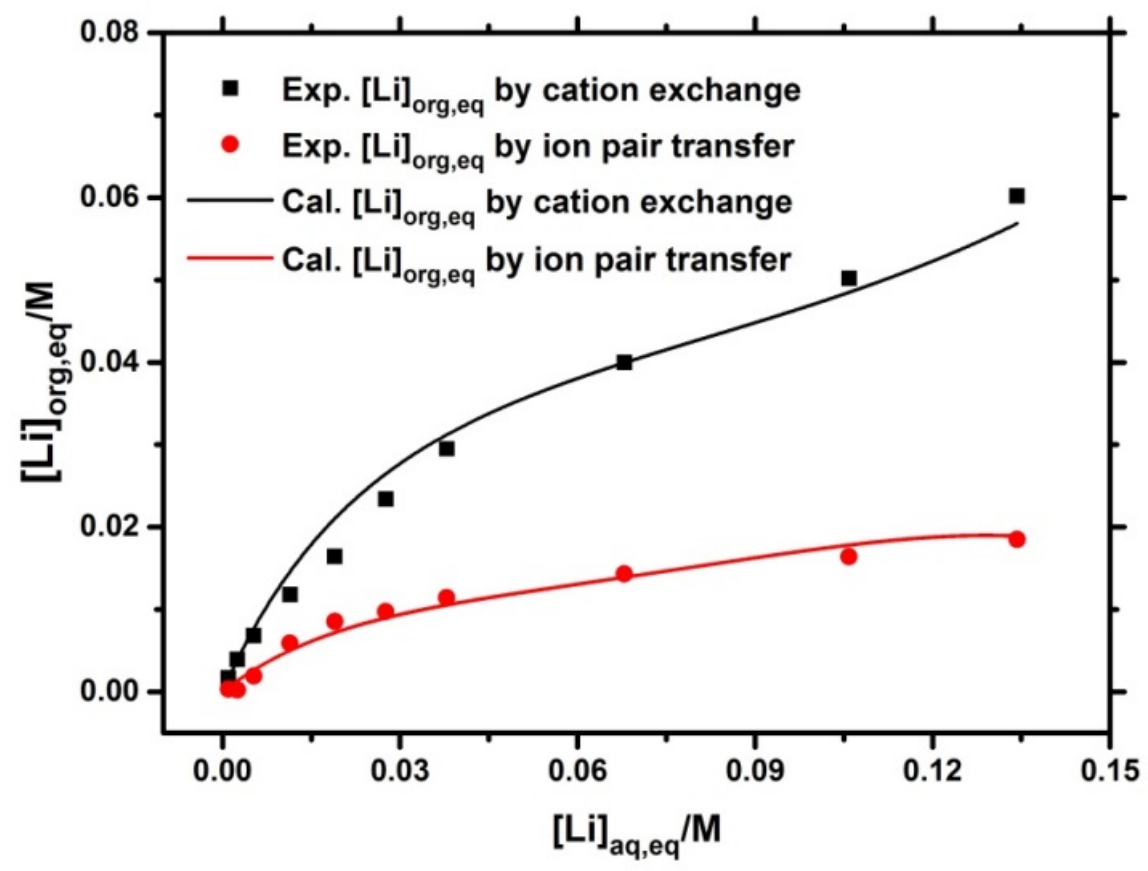

Figure 8. Experimental and calculated equilibrium isotherms for the extraction of lithium from water by both mechanisms (cation exchange and ion pair extraction) using 40 vol. $\% \mathrm{TBP} /\left[\mathrm{C}_{2} \mathrm{mim}\right]\left[\mathrm{Tf}_{2} \mathrm{~N}\right]$. The concentrations are expressed in moles per liter. 
Table 2. Equilibrium constants and stoichiometric coefficients values, for both lithium extraction mechanisms by $\mathrm{TBP} /\left[\mathrm{C}_{2} \operatorname{mim}\right]\left[\mathrm{Tf}_{2} \mathrm{~N}\right]$.

\begin{tabular}{|l|l|l|}
\cline { 2 - 3 } \multicolumn{1}{c|}{} & Cation exchange & Ion pair transfer \\
\hline Stoichiometry & $\mathrm{n}=3$ & $\mathrm{~m}=4$ \\
\hline Equilibrium constant & $\mathrm{K}_{1}=0.010 \pm 0.003$ & $\mathrm{~K}_{2}=3.30 \pm 0.09$ \\
\hline $\mathrm{R}^{2}$ & 0.98 & 0.98 \\
\hline
\end{tabular}

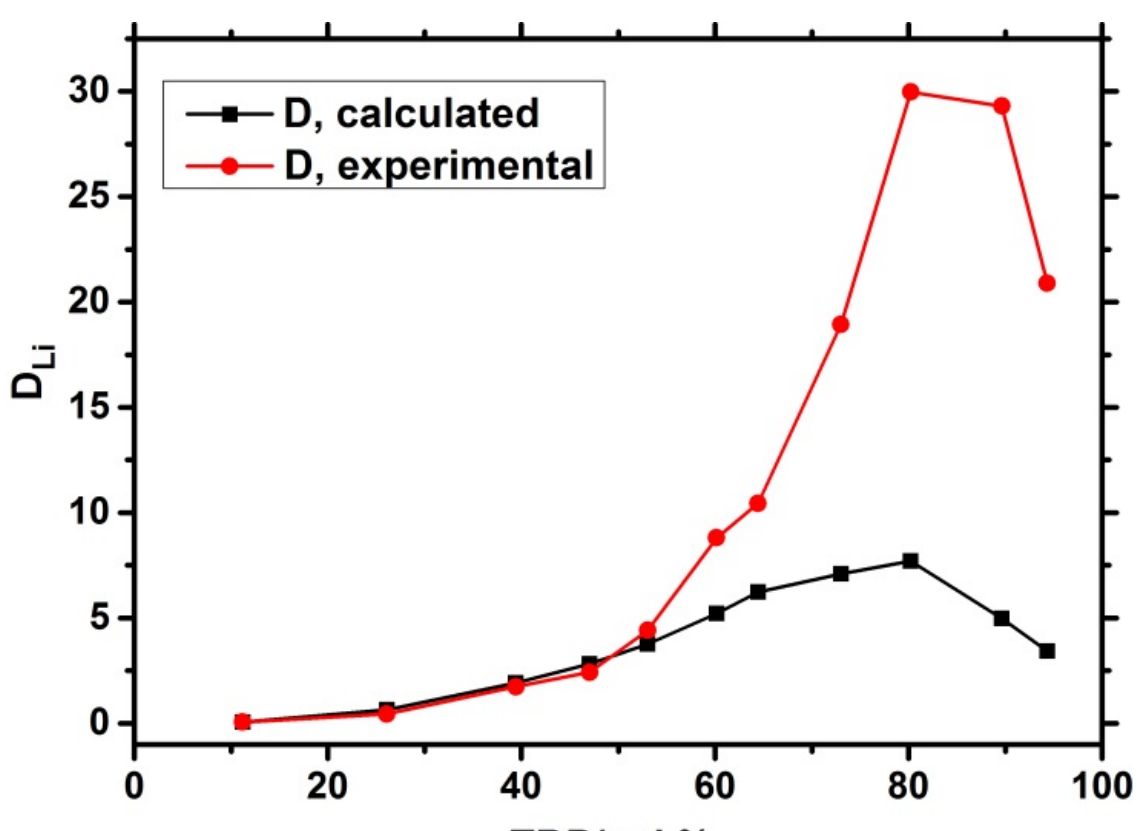

TBP/vol. $\%$

Figure 9. Experimental and calculated distribution ratios of lithium in the case of $\mathrm{LiCl}$ $/ \mathrm{HCl} / / \mathrm{TBP} /\left[\mathrm{C}_{2} \mathrm{mim}\right]\left[\mathrm{Tf}_{2} \mathrm{~N}\right]\left(\mathrm{pH}=2\right.$ and $\left.\left[\mathrm{Li}^{+}\right]_{\text {aq,init }}=15.4 \pm 0.8 \mathrm{mmol} . \mathrm{L}^{-1}\right)$. The concentrations are expressed in moles per liter. 

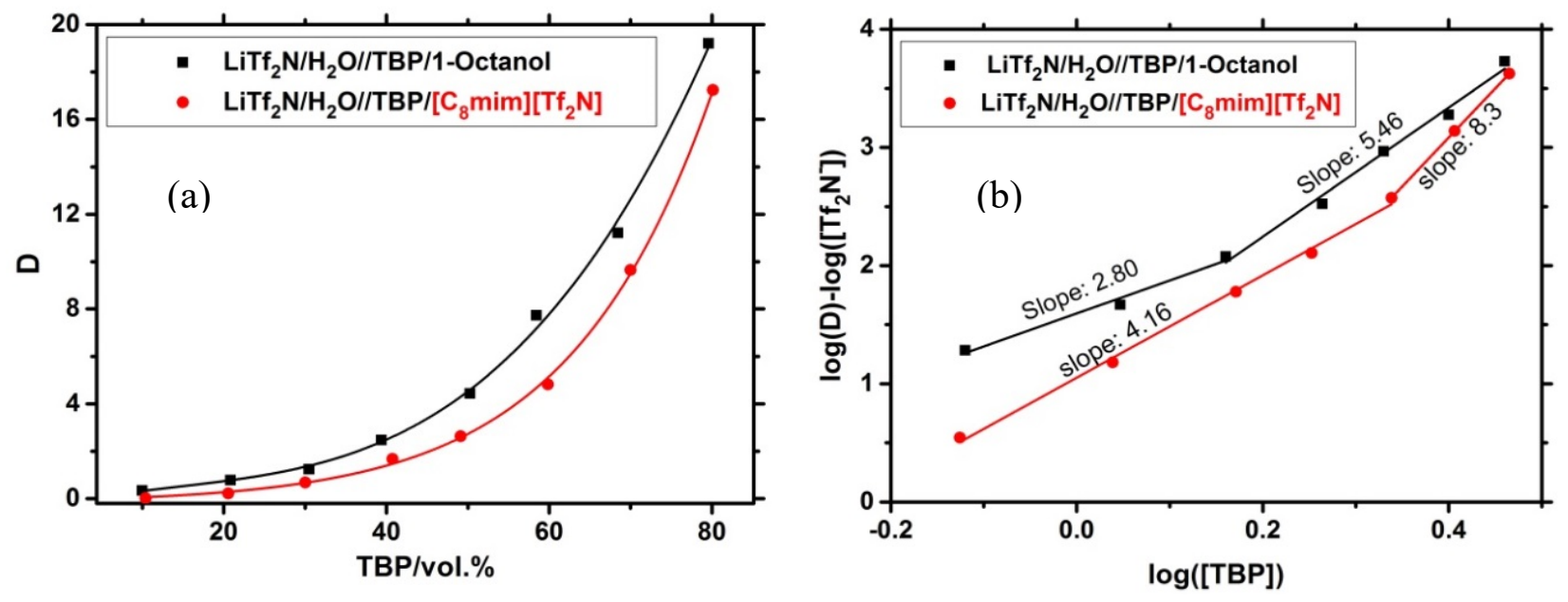

Figure 10. (a): Effect of TBP concentration on the extraction of lithium ions and (b):

Plot of $\left(\log D_{\mathrm{Li}^{-}}\left[\mathrm{Tf}_{2} \mathrm{~N}^{-}\right]_{\mathrm{aq}}\right)$ versus $\log [\mathrm{TBP}]$ (aqueous phase: pure DI water with $\left.\left[\mathrm{Li}^{+}\right]_{\text {aq,init }}=72.6 \pm 3.6 \mathrm{mmol} \cdot \mathrm{L}^{-1}\right)$.

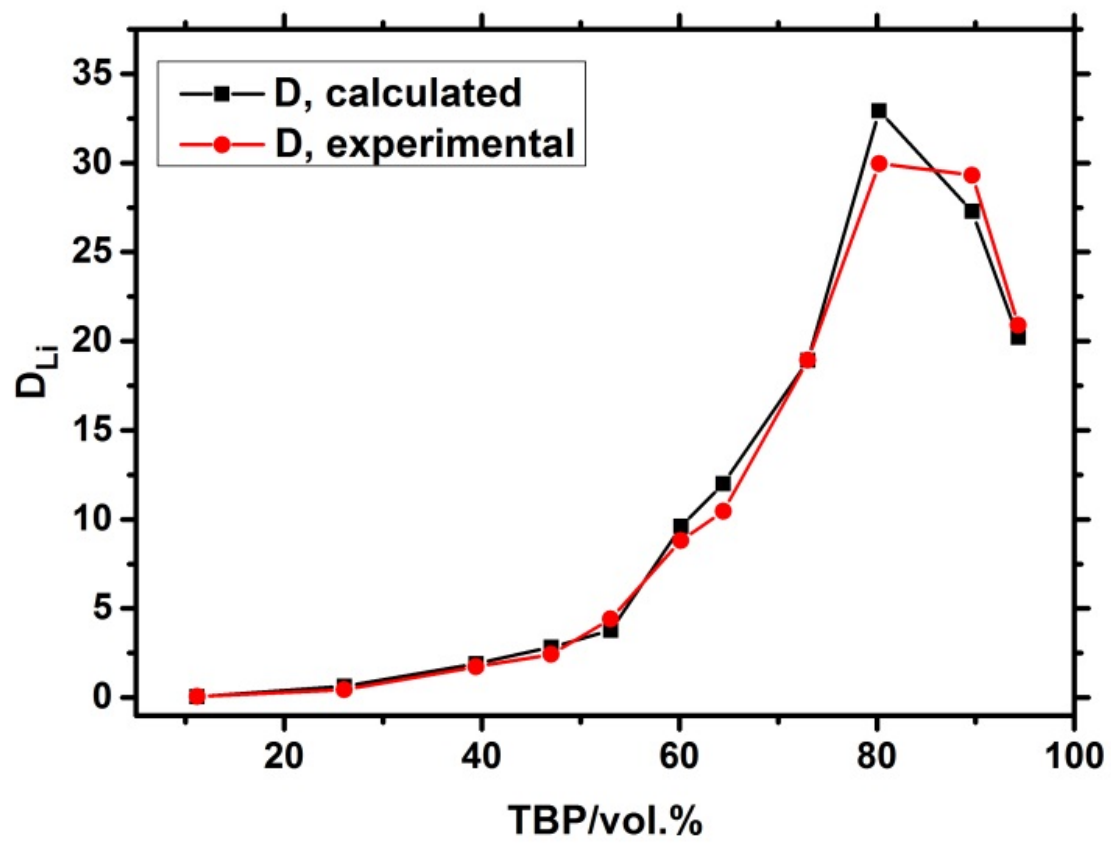

Figure 11. Experimental and calculated distribution ratios of lithium in the case of LiCl $/ \mathrm{HCl} / / \mathrm{TBP} /\left[\mathrm{C}_{2} \mathrm{mim}\right]\left[\mathrm{Tf}_{2} \mathrm{~N}\right]\left(\mathrm{pH}=2\right.$ and $\left.\left[\mathrm{Li}^{+}\right]_{\mathrm{aq}, \text { init }}=15.4 \pm 0.8 \mathrm{mmol} . \mathrm{L}^{-1}\right)$. 